\title{
Performance of Buildings under Earthquakes in Barcelona, Spain
}

\author{
Alex H. Barbat* \\ Department of Structural Mechanics, Civil Engineering School, Technical University of Catalonia, Edificio C1, \\ Campus Norte UPC, Jordi Girona 1-3, 08034, Barcelona, Spain
}

\&

Luis G. Pujades \& Nieves Lantada

Department of Soil Mechanics, Civil Engineering School, Technical University of Catalonia, Edificio D2, Campus Norte UPC, Jordi Girona 1-3, 08034, Barcelona, Spain

\begin{abstract}
The seismic risk of the buildings of Barcelona, Spain, is analyzed by using a method based on the capacity spectrum. The seismic hazard in the area of the city is described by means of the reduced 5\% damped elastic response spectrum. Obtaining fragility curves for the most important building types of an urban center requires an important amount of information about the structures and the use of nonlinear structural analysis tools. The information on the buildings of Barcelona was obtained by collecting, arranging, improving, and completing the database of the housing and current buildings. The buildings existing in Barcelona are mainly of two types: unreinforced masonry structures and reinforced concrete buildings with waffled slab floors. In addition, the Arc-View software was used to create a GIS tool for managing the collected information to develop seismic risk scenarios. This study shows that the vulnerability of the buildings is significant and therefore, in spite of the medium to low seismic hazard in the area of the city, the expected seismic risk is considerable.
\end{abstract}

\section{INTRODUCTION}

The term earthquake risk is usually understood as the potential physical, economic, social, and environmental

*To whom correspondence should be addressed. E-mail: alex.barbat@ upc.es. consequences of seismic events that may occur in a specified area unit and period of time. Its estimation requires a multidisciplinary approach that takes into account not only the expected physical damage understood as the damage suffered by structures, the number and type of casualties or the economic losses, but also social, organizational, and institutional factors. At the urban level, for example, vulnerability also should be related to the social fragility and the lack of resilience of the exposed community, that is, to its capacity to absorb the impact and control its implications. Nevertheless, a holistic approach to estimate risk aiming to guide the decision making at the urban level should start with the evaluation of scenarios of physical damage as an essential tool, because they are the result of the convolution between hazard and physical vulnerability for buildings and infrastructure (Barbat et al., 1996; Carreño et al., 2006; Barbat et al., 2006). Accordingly, the evaluation of physical seismic vulnerability and risk is the main purpose of this article, but some possibilities of evaluating the number of casualties and the economic losses are also examined. Some definitions related to these concepts are introduced here below (Coburn and Spence, 2002):

Risk: Rie $\left.\right|_{T}$, can be defined as the probability of loss or as the loss average in an exposed element $e$ as a consequence of the occurrence of an event with intensity larger than or equal to $i$ during an exposition period $T$. 
Hazard: $\left.\mathrm{Hi}\right|_{T}$, can be understood as the probability or as the average expected rate of occurrence of an event with an intensity greater than or equal to $i$ during an exposition period $T$.

Vulnerability: Ve, is the intrinsic predisposition of the exposed element $e$ to be affected or of being susceptible to suffer a loss as a result of the occurrence of an event with intensity $i$.

Starting from these definitions, risk is a function $f$ of the convolution between hazard $\mathrm{Hi}$ and vulnerability $\mathrm{Ve}$ during an exposition period $T$

$$
\left.\mathrm{Rie}\right|_{T}=\left.f(\mathrm{Hi} \otimes \mathrm{Ve})\right|_{T}
$$

where the symbol $\otimes$ stands for convolution (Cardona and Barbat, 2000).

In this article we develop risk scenarios for residential buildings in an urban area in the following steps:

. Definition of earthquake hazard scenarios; both deterministic and probabilistic cases are considered herein.

2. Classification of the buildings into categories with similar earthquake behavior.

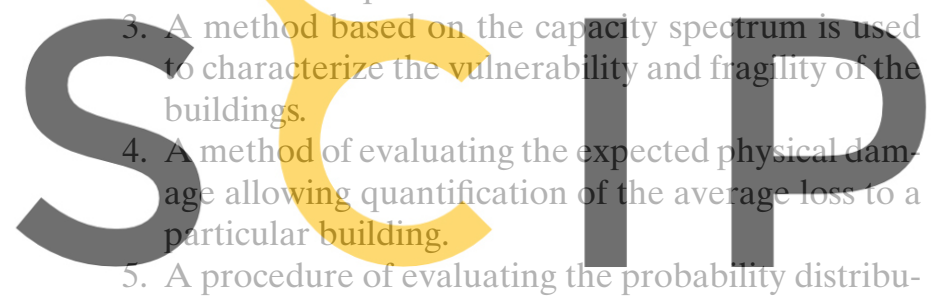
tion for the selected damage states of each building.

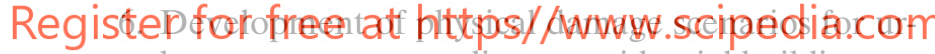
ban areas corresponding to residential buildings.

7. Application of existing empirical relations providing the number of lives that could be lost in average, the amount of debris produced by the seismic crisis, and the average economic cost due to the physical damage in residential buildings obtained in point 6 .

Uncertainties are high in most of the previous steps. These are particularly high in the estimation of the seismic hazard in low to moderate seismic areas and in the vulnerability estimation of existing buildings. Nevertheless, it is not our purpose to perform a probabilistic study in the strict sense, obtaining confidence intervals, performing sensitivity tests, and analyzing the corresponding uncertainties propagating errors in the model. The performed analyses are based on average, expected, or most probable values.

The seismic risk of the city is analyzed by using this procedure. The city of Barcelona, Spain, is located in an area of low seismic hazard, but its buildings show a high vulnerability and, consequently, a significant probability of being damaged even in the case of a not excessively severe earthquake. Most of its residential build- ings have an unreinforced masonry structure. In many districts like, for instance, the Eixample, these types of buildings are tall, have an average age of 60 years and have been designed and built without the consideration of any earthquake resistant criterion. Additionally, they have some particular features, typical for the construction techniques of the city at that time, which have been identified as potential damage sources. Most of the reinforced concrete buildings of Barcelona have waffled slab floors, which significantly influences their vulnerability; this is a structural class that is not adequate for seismic areas. The expected seismic performance of the buildings is evaluated by means of structural analyses whose most relevant results are capacity curves (Barbat et al., 1997). In the case of unreinforced masonry buildings, the analysis model consisted of macro elements describing the nonlinear in-plane mechanical behavior of the masonry panels. In the case of reinforced concrete buildings with waffled slab floors, equivalent columns-and-beams models have been used to assess the expected damage. Specific fragility curves have been developed in the frame of this study for both masonry and reinforced concrete buildings, which are the
main building types in Barcelpna. Reliable structural
models allowing calculation of the capacity spectra and
fragiity curves have been obtained by considering the
constructive peculiarities of the existing buildings. De-
tailed information on their design has been obtained
over the years by collecting, arranging, improving, and completing the database of the housing and buildings of

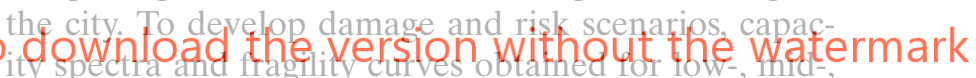
and high-rise unreinforced masonry and reinforced concrete buildings have been applied. The seismic performance results show the high vulnerability of this type of building and the need of retrofitting to improve seismic behavior.

\section{THE STUDIED URBAN AREA AND THE BUILDING TYPES}

The "Eixample," a district in the central part of Barcelona, Spain, designed in the middle of the nineteenth century, is likely the most emblematic and representative district of Barcelona. Covering about 750 hectares, it consists of almost symmetric squared blocks sizing about $113 \mathrm{~m} \times 113 \mathrm{~m}$. These blocks are perfectly aligned and are beveled in their vertices by edges of about $20 \mathrm{~m}$. The most representative structural type corresponds to unreinforced masonry buildings, whose large number greatly influences the overall seismic vulnerability of the city. The construction of this district took place between 1860 and 1950, with an average of 
25 buildings for each block, which were designed only to vertical static loads, without any consideration of seismic design criteria. Similar masonry buildings can also be found in many European and Mediterranean old and historic cities. In some seismic areas, certain measures of seismic protection have been applied in the past. But, there are also many common buildings in such poor condition that they have to be classified in the highest vulnerability class of the European Macroseismic Intensity Scale (EMS-98) (Grünthal 1998). The unreinforced masonry buildings in Barcelona are an example of such a case. They are tall and with openings of considerable size and number, which affect their vulnerability, increased even more by long walls without perpendicular stiffening. The floors of these unreinforced masonry buildings are made of wooden, steel, or pre-cast concrete beams with small ceramic vaults in between, according to the building period, showing a poor stiffness both to bending moment and to axial forces. Due to the greater height of their first floors, almost all of these buildings have two soft storeys. In many cases, cast iron columns were used instead of masonry walls at the base and ground floors, thus reducing their stiffness even more.

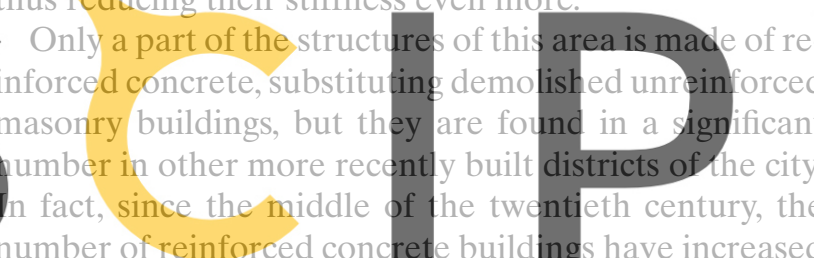

in modern cities, making the reinforced concrete nowa-

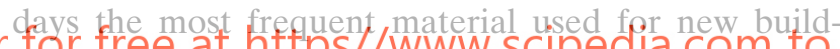

Register days the most frequent material used for new build-

vary extremely in appearance and design and show a large scattering of earthquake resistance. The European Macroseismic Intensity Scale (EMS-98; Grünthal, 1998) assigns a very wide range of vulnerability to the framed reinforced concrete buildings used in Europe, which may cover the whole vulnerability range from buildings without earthquake-resistant design to engineered buildings designed with high-level seismic codes. In extreme cases, their vulnerability can be comparable with that of lowquality unreinforced brick masonry buildings. The behavior of similar structures during recent earthquakes confirms this wide range of vulnerability. Moreover, several studies show that framed reinforced concrete buildings with regular structural configurations of the central and eastern United States demonstrate good seismic behavior, concluding that, in this seismic area and for this type of structure, the design for gravity loads provides sufficient stiffness for an adequate seismic performance. The reinforced concrete buildings of Barcelona studied in this article fall within the high vulnerability part of the EMS-98 scale, for which this scale predicts significant damage for relatively low seismic intensities. It has to be pointed out that most of the reinforced concrete buildings of Barcelona are not moment-resisting frames, but typically column and slab buildings in their waffled slab floor version, which belong to a structural type not adequate for seismic areas due to their low ductility. The Spanish code limits their ductility factor to two, while earthquakes, as for instance Kokaeli, Turkey (1999), have dramatically shown the high seismic vulnerability of this kind of building. In addition, many of these buildings have soft first storeys.

In general, buildings in Barcelona are part of aggregates, forming building blocks. In the past, designers, architects, and builders have not been careful at all when joining new buildings to older existing ones. Important differences in the number of storeys and in the height of the floors are very frequent within a block. Nevertheless, there is no possibility of pounding because adjacent buildings have a common wall, but this characteristic increases the seismic vulnerability of these structures. The seismic analysis of a whole block is a complex problem which is not an objective of this article, but which is foreseen as a future work.

Three main information sources were used in obtain-

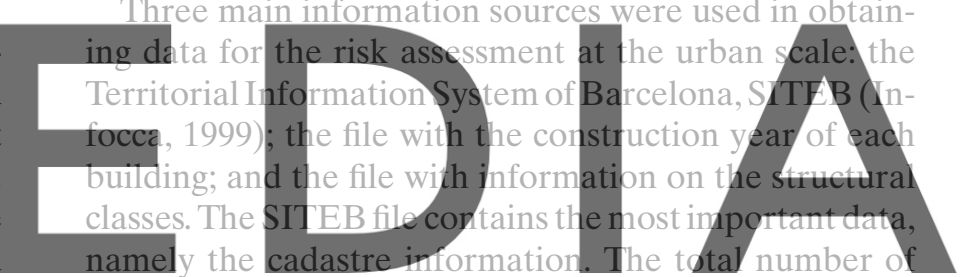

cadastre units or lots in the city is 80,715 and they may downtaa d the version withput the watermark like perimeters and number of storeys of each built lot. A set of blocks composes the so-called small statistical zones, which are used for administrative purposes and are the basis for the census. These census zones, 248 in total, have been used to map risk scenarios; a relatively small number of them make up a neighborhood, whose total number is 38 , and a small number of neighborhoods make up a district whose total number is 10 .

According to the official statistics of Barcelona corresponding to the year 2000 (Departament d'Estadistica, 2000), Barcelona has about 1.566 million inhabitants, 700,000 housing units, and 69,000 buildings, with an average of about 2.24 inhabitants in each. The Municipality of Barcelona provided the cadastre database, which is well described in the report Infocca (1999), and detailed information concerning the age and kind of buildings. The collected data allowed complete characterization of geometrical features and geographical location together with the type and year of construction of about 63,000 buildings (that are more than $91 \%$ of the total number of buildings), which mainly correspond 


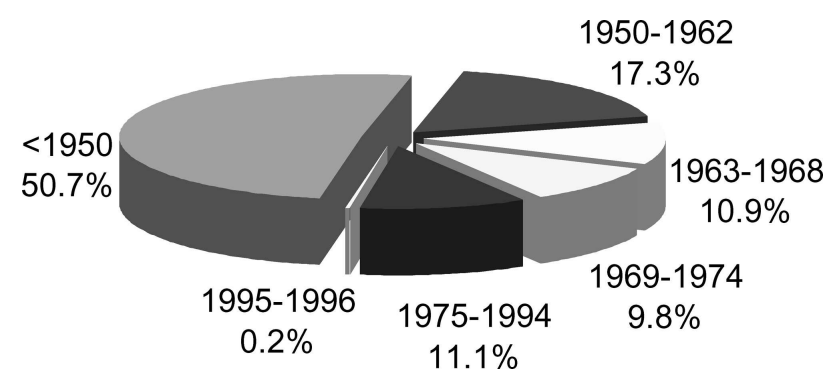

Fig. 1. Distribution of the age of the buildings.

to residential buildings. For the others, that is, about 6,000 buildings, there is a lack of information about one or more of the mentioned characteristics. There are 60,653 masonry and reinforced concrete buildings, which represent $96.3 \%$ of the total number of residential buildings and only these have been included in the simulations performed in this study.

Figure 1 shows the age distribution as a function of the constructive periods in Spain, which have been defined based on seismic resistant considerations. It can be

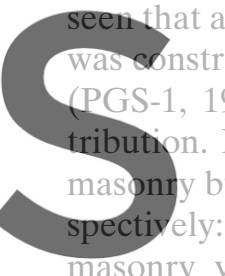
at almost $80 \%$ of the buildin structed prior to the first 968). Figure 2 shows In this figure, M31, M buildings with the follo

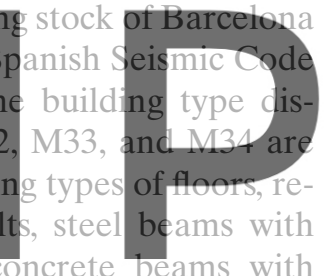
masonry vaults. RC32 are reinforced concrete build-

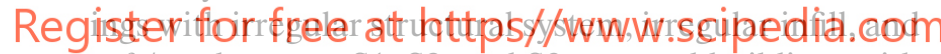
soft/weak storey. S1, S2, and S3 are steel buildings with moment frames, braced frames, and frames with unreinforced masonry infill walls. S5 corresponds to steel and RC composite systems. These codes have been developed, within the RISK-UE European project, to describe in a detailed way all the building types identified in Europe (Lungu et al., 2001). About $97 \%$ of the buildings have masonry and reinforced concrete structure.

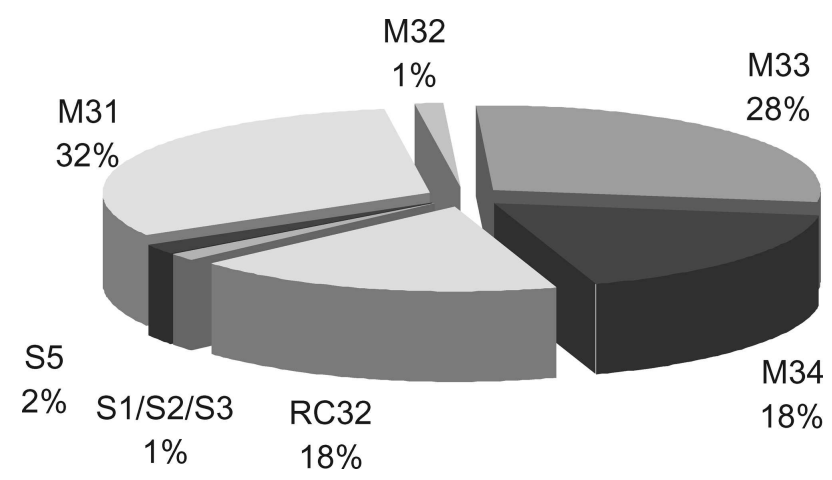

Fig. 2. Distribution of the building types.
All this information is essential in assigning expected damage values to the buildings. To obtain more realistic damage scenarios, specific capacity spectra and fragility curves have been developed for these typical buildings of Barcelona. Although the number of low-rise reinforced concrete buildings is very low and not significant among the total building stock of the city, for completeness, low-medium-, and high-rise buildings have been considered in the analysis, developing the corresponding capacity spectra, and fragility curves.

\subsection{Seismic hazard}

Barcelona, a city located in the northeastern part of Snain has a moderate seismicity and weak tectonic motions (Egozcue et al., 1991). Its seismic hazard has been recently re-evaluated defining the action in terms of elastic response acceleration spectra both from a deterministic and a probabilistic point of view (Irizarry et al., 2003). Two earthquake scenarios have been developed and used to perform the simulations of seismic risk scenarios-one deterministic, based on a historical earthquake that occurred quite far from the city and

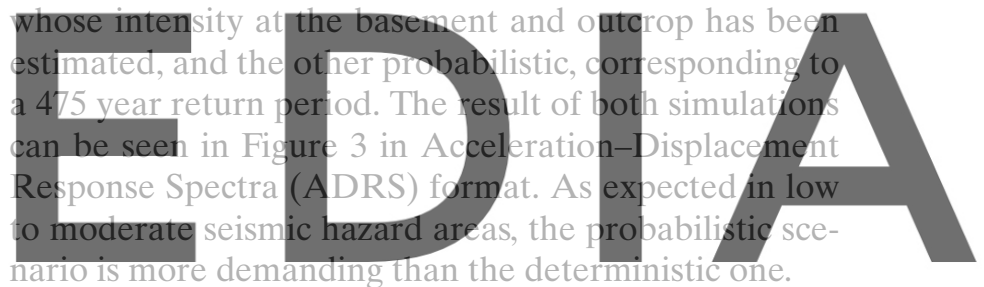

The seismic zoning (Cid, 1998) has been taken into

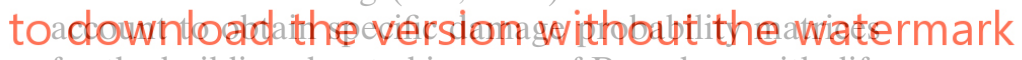
for the buildings located in areas of Barcelona with different soil characteristics. Figure 4 shows the four main seismic zones of the city: zone R corresponds to rock outcrops; soils in zone I are soft, while zones II and III are made of intermediate soils. Typical shear velocities for these zones are, 800, 225, 394, and $405 \mathrm{~m} / \mathrm{s}$, respectively. Figure 5 shows the response spectra corresponding to these soil types (Irizarry et al., 2003). These elastic response spectra are the bases for obtaining smoothed demand spectra, which are used in the calculation of the expected displacement demand.

\subsection{Structural capacity}

An important objective of this study was to produce building-by-building risk scenarios that required the seismic characterization of about 60,653 residential buildings. It was decided to adopt a simplified building typology matrix (six models) reasonably representing the wide number of buildings but showing similar structural characteristics, and selected, representative, existing buildings have been analyzed by using simplified structural analysis models but reasonably describing 


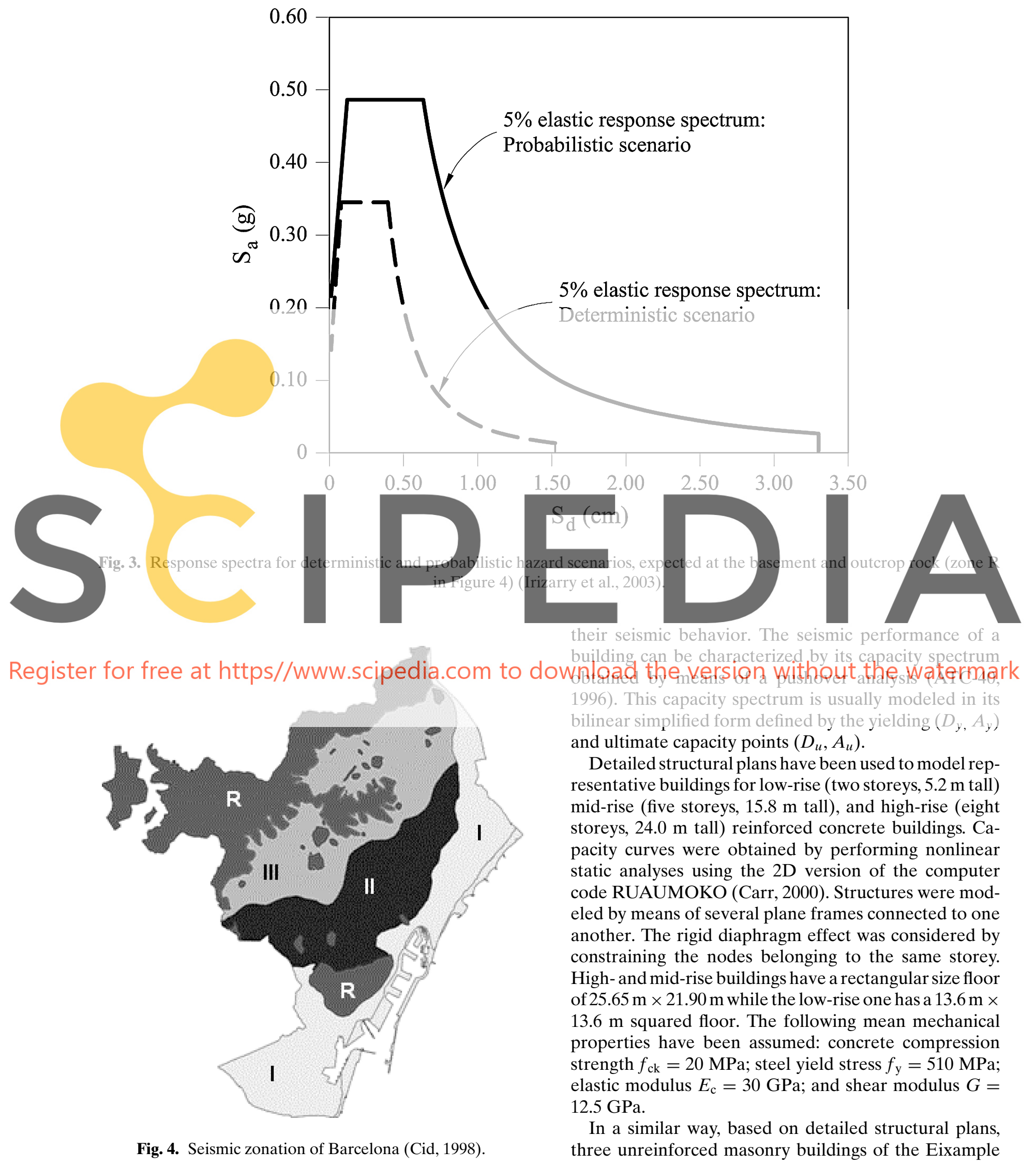




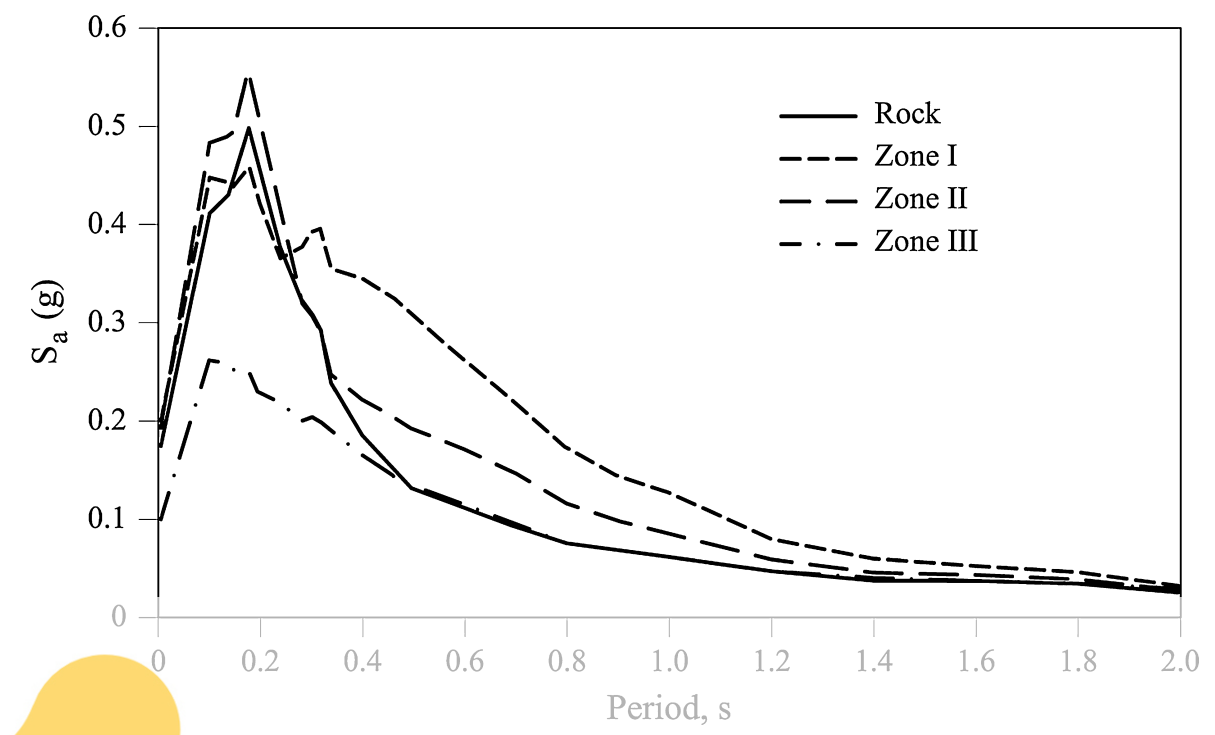

Fig. 5. Probabilistic seismic response spectra for the different soil conditions of Barcelona (Irizarry et al., 2003).

district of Barcelona have been modeled. An old build-

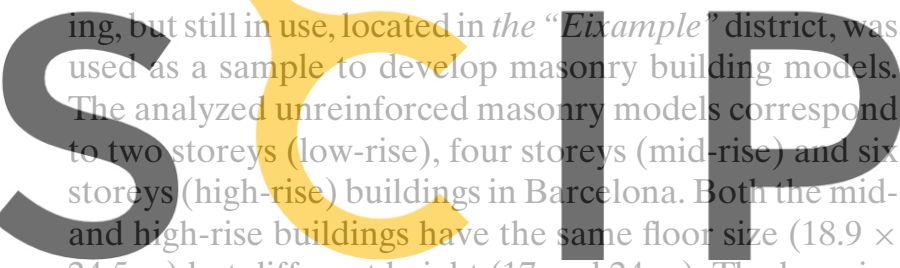

$24.5 \mathrm{~m}$ ) but different height (17 and $24 \mathrm{~m}$ ). The low-rise building has a $7.3 \mathrm{~m} \times 9.3 \mathrm{~m}$ in floor and is $6.65 \mathrm{~m}$ tall. This

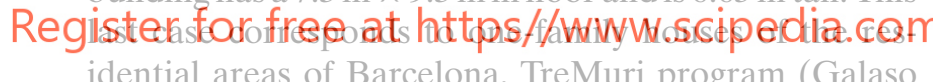
idential areas of Barcelona. TreMuri program (Galaso ings. This program is a useful tool to study the nonlinear in-plane mechanical behavior of masonry panels and to assess the expected damage for masonry buildings due to earthquakes. TreMuri program allows performing structural analyses with 3D models. In spite of the local flexural behavior of floors and walls, the out-of-plane response was not included in the analysis because its effect on the global building response was not considered to be significant in this case where vertical and horizontal structural elements are not properly connected. The use of these tools guaranteed the computation of fragility curves and damage probability matrices for more than $95 \%$ of the residential building stock of the city, allowing the development of representative risk scenarios, which was the main goal of the study.

The capacity function, calculated by loading monotonically the structure with a force according to a given load pattern and determining, by means of a nonlinear analysis, the associated deformation, is the well-known pushover curve. Although this analysis is based on the simplified assumption of bilinear strength-deformation behavior of the structure, this simple and efficient and-
ysis allows us to study the performance of a building
under seismic actions (Reinhorn, 1997). Usually, theca-
pacity curves are developed based on the assumption
that the response of the structure is well represented
by the fundlamental mode of vibration. This Assumption would be inaccurate for flexible buildings, with a fundamental period higher than 1 second (ATC-40,

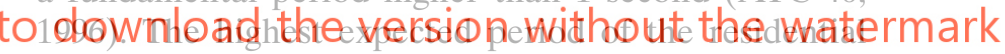
buildings existing in Barcelona is about 1 second and it corresponds to high-rise reinforced concrete buildings. Consequently, in spite of the limitations of the pushover analysis, for the purpose of this study, which was the calculation of seismic risk scenarios for the whole city, the use of simplified capacity curves together with predetermined demand spectra, provides a reasonably good approximation of the expected damage of the residential buildings of Barcelona. A pushover analysis allowed us to obtain the capacity curves for each building class and, starting from these curves, capacity spectra have been obtained (ATC-40, 1996). Figure 6 shows an example of the capacity spectrum for mid-rise reinforced concrete buildings. Figure 7 shows the corresponding spectrum for mid-rise unreinforced masonry buildings. The bilinear representations of the capacity spectra are also shown in these figures. The load patterns used in the pushover analyses correspond to the fundamental mode of vibration of the structure in the analysis direction. More sophisticated dynamic analyses could be appropriate for detailed evaluations of individual special buildings. 


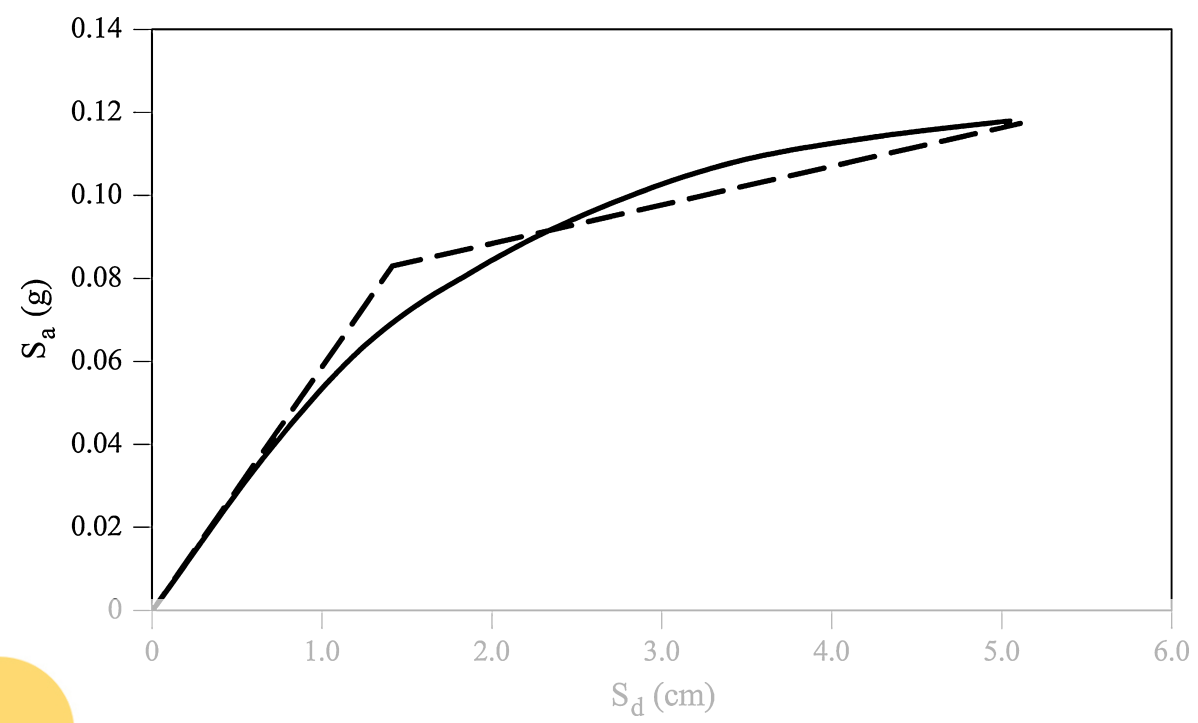

Fig. 6. Pushover and bilinear capacity spectra and their bilinear representation for mid-rise reinforced concrete buildings.

Table 1 shows the yield and ultimate capacity points defining the bilinear capacity spectra for reinforced con$S$ crete and masonry buildin he corresponding plots. be observed in Figure 9 for onry buildings. This fact xcessive slenderness of the failure criterion used in fact, the nonlinear macro-element model, representa tive of a whole masonry panel, proposed by Gam-

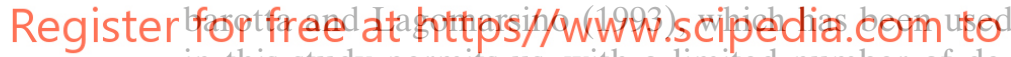
in this study permits us, with a limited number of degrees of freedom, to represent the two main masonry failure modes, bending-rocking and shear-sliding (with

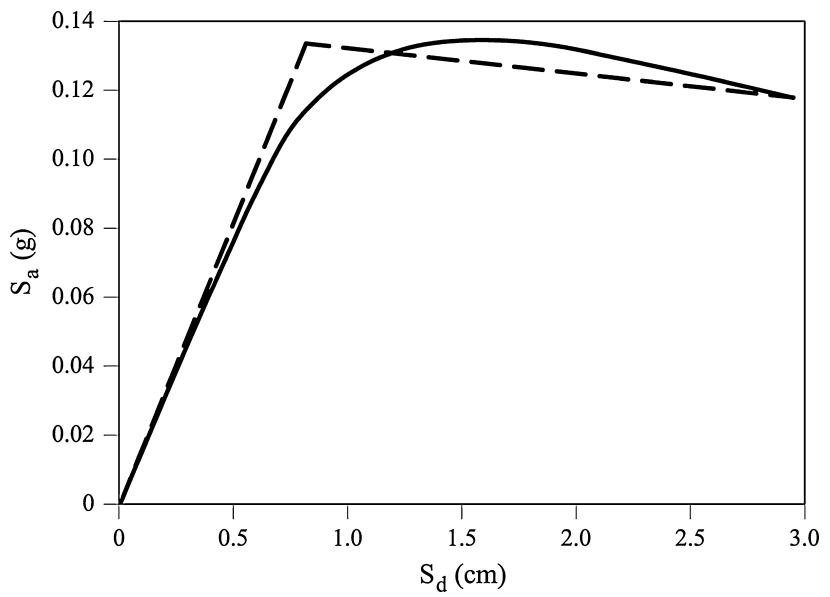

Fig. 7. Pushover and bilinear capacity spectra and their bilinear representation for mid-rise unreinforced masonry buildings.
Table 1

Yield and ultimate capacity for reinforced concrete (RC) and

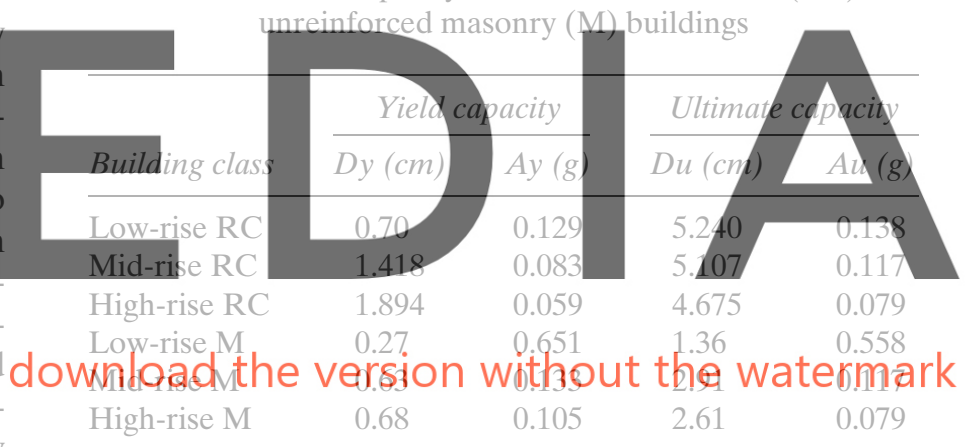

friction) mechanisms, on the basis of mechanical assumptions. This model, one of the few existing tools adequate to model masonry buildings of the type existing in Barcelona, considers, by means of internal variables, the shear-sliding damage evolution, which controls the strength deterioration (softening) and the stiffness degradation. It also can be seen in Figures 8 and 9, how the capacity decreases with the height of the building both for masonry and for RC buildings. The capacity spectrum for low-rise masonry buildings has not been plotted in Figure 9 because of the high yield and ultimate spectral acceleration values. In fact, this type of building is representative of a number of one-family houses, mainly located in the residential districts of the city.

\subsection{Fragility curves}

For a given damage state, a fragility curve provides the probability of reaching or exceeding the damage state 


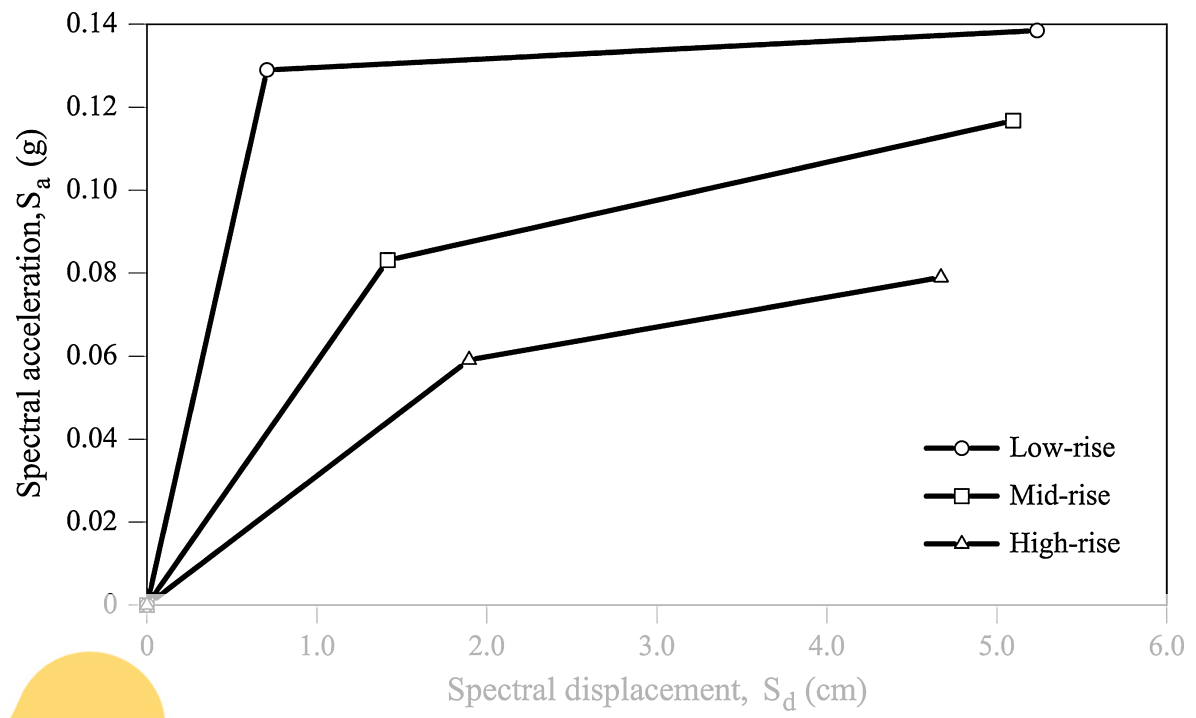

as a function of a parameter which describes the seismic action to which the building is subjected. Let this param-
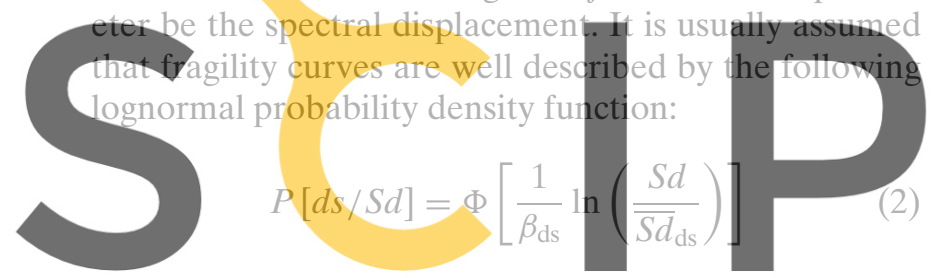

where $\overline{S d}_{\mathrm{ds}}$ is the threshold spectral displacement at Register for perobability of the damage state ds is 50\%

of this spectral displacement, $\Phi$ is the standard normal cumulative distribution function, and $S d$ is the spectral displacement. Figure 10 and Table 2 show how the $\overline{S d}_{\mathrm{ds}}$

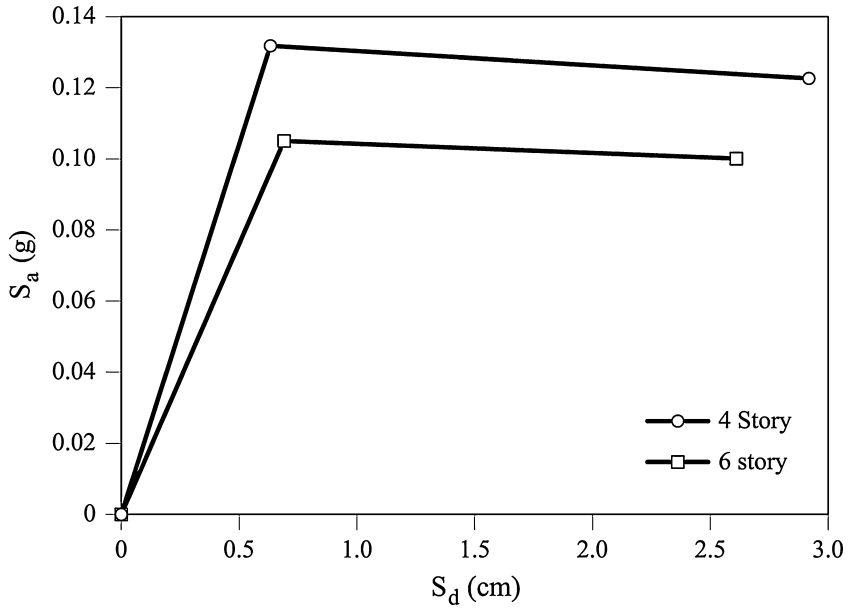

Fig. 9. Bilinear capacity spectra for mid- and high-rise unreinforced masonry buildings.

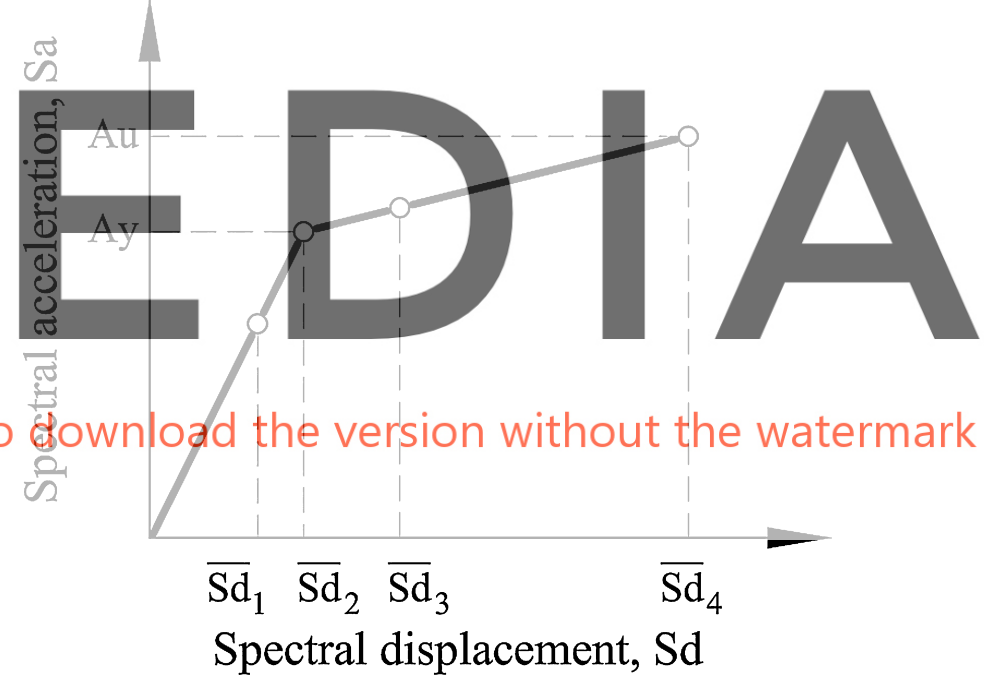

Fig. 10. Damage state thresholds from capacity spectrum.

thresholds are obtained from the capacity spectra. Concerning $\beta_{\mathrm{ds}}$, it is well known that the expected seismic damage in buildings follows a binomial probability distribution (Grünthal, 1998). Therefore, it is assumed that

Table 2

Damage state thresholds defined in agreement with the capacity spectrum

$\begin{array}{ll}\overline{\overline{S d_{1}}}=0.7 D_{y} & \text { Slight } \\ \overline{S d_{2}}=D_{y} & \text { Moderate } \\ \overline{S d_{3}}=D_{y}+0.25\left(D_{u}-D_{y}\right) & \text { Extensive } \\ \overline{S d_{4}}=D_{u} & \text { Complete }\end{array}$


Table 3

Probabilities of the expected damage states when fixing a $50 \%$ probability for each damage state

\begin{tabular}{lccccc}
\hline Condition & $\mu_{D}$ & $P_{\beta}(1)$ & $P_{\beta}(2)$ & $P_{\beta}(3)$ & $P_{\beta}(4)$ \\
\hline$P_{\beta}(1)=0.5$ & 0.911 & 0.500 & 0.119 & 0.012 & 0.00 \\
$P_{\beta}(2)=0.5$ & 1.919 & 0.896 & 0.500 & 0.135 & 0.008 \\
$P_{\beta}(3)=0.5$ & 3.081 & 0.992 & 0.866 & 0.500 & 0.104 \\
$P_{\beta}(4)=0.5$ & 4.089 & 1.000 & 0.988 & 0.881 & 0.500
\end{tabular}

Note: 1 -slight, 2-moderate, 3-extensive, and 4-complete.

at the $\overline{S d}_{\mathrm{ds}}$ threshold, the probability of this damage state is $50 \%$ and then the probabilities of the remaining damage states are estimated.

The method for analyzing the seismic damage considers five damage states: none, slight, moderate, extensive, and complete. Fragility curves have been obtained starting from the bilinear representation of capacity curves. Table 3 shows the cumulative expected probabilities of all the damage states when a particular damage state probability is fixed to $50 \%$ and a binomial or equivalent beta probability disuribution table, the damage states from 1 to 4 for damage sta tively. Parameter $\mu_{D}$ cont distribution. Finally, the fur 2) is fitted to the obtained points square criterion.

Figures 11 and 12 are examples of such kinds of fit.

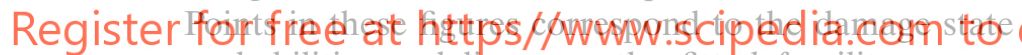
probabilities and lines are the fitted fragility curves. Figure 11 corresponds to the mid-rise reinforced concrete building class. Figure 12 shows the fragility curves obtained for the cases of mid-rise unreinforced masonry buildings. Curves of Figures 11 and 12 are representative for most of the buildings of Barcelona. Table 4 shows the corresponding parameters, namely $\overline{S d}_{i}$ and $\beta_{i}$, where $i=1, \ldots, 4$ defines the fragility curves corresponding to reinforced concrete and unreinforced masonry building classes.

It can be seen how reinforced concrete buildings have a better seismic performance than masonry buildings. For example, in the case of a 4-cm spectral displacement, the expected probability for the complete damage state is about $30 \%$ for concrete buildings while it is more than $60 \%$ for masonry buildings. Fortunately, Barcelona is located in an area of low seismic hazard, but the analyses clearly point out the very high vulnerability of the buildings and, consequently, a significant probability of damage even in the case of a not too severe earthquake. Anyway, it is somewhat surprising that the obtained results show high expected seismic damage for relatively low spectral displacements. They indicate that the reinforced concrete buildings with waffled slab floors are really weak, which is a reasonable result when taking into account the particular structural type described above.

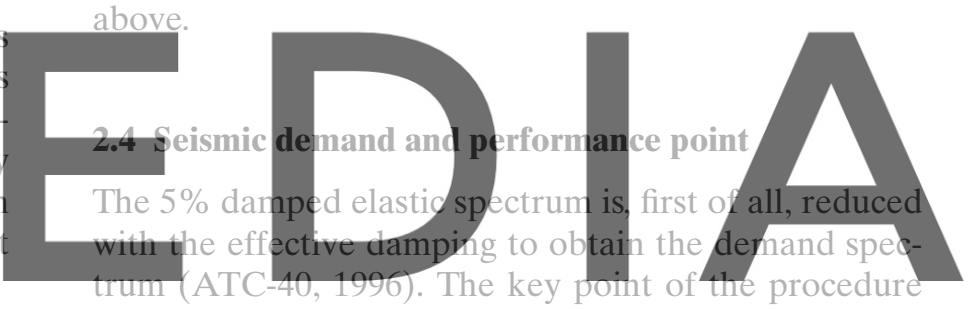

starts from the demand and capacity spectra. Crossing

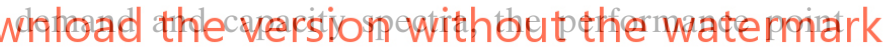
is established and thus the expected spectral displacement. Entering then with this value in the corresponding fragility curves, probability damage matrices for the corresponding hazard scenario are obtained.

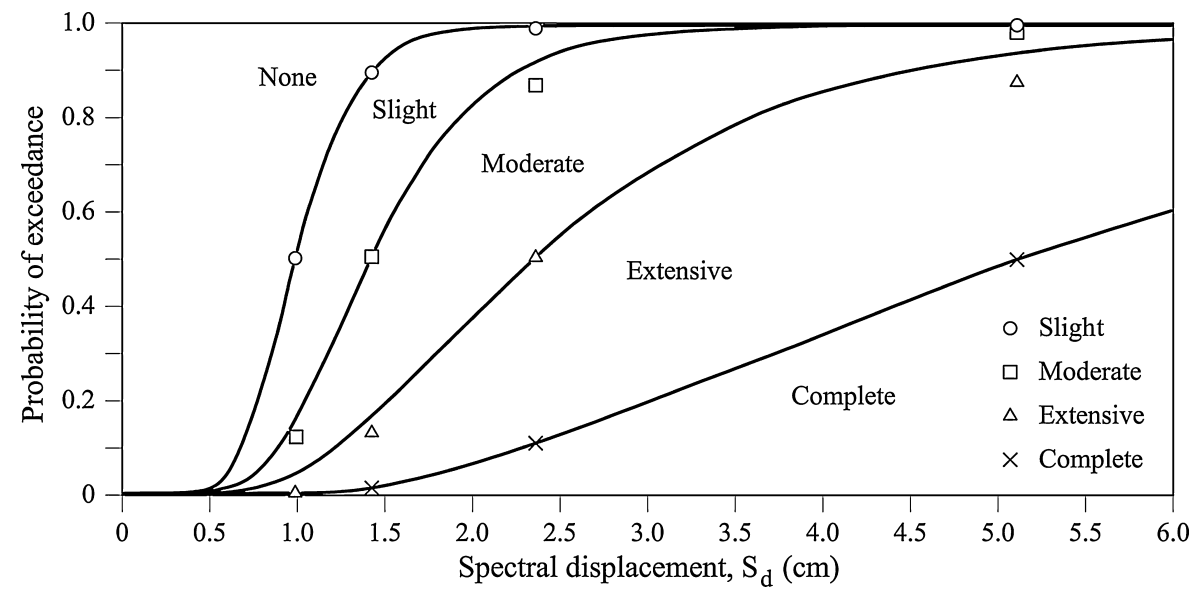

Fig. 11. Fragility curves for mid-rise reinforced concrete buildings. 


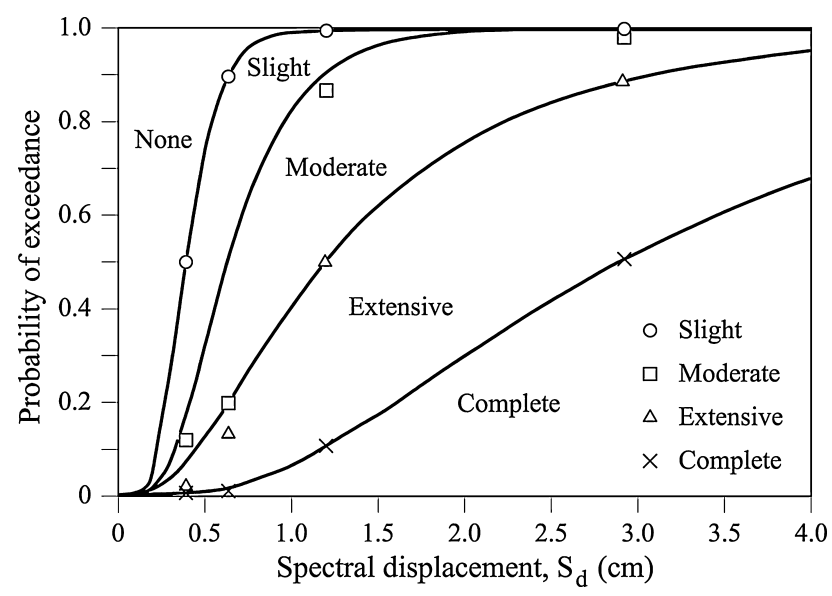

Fig. 12. Fragility curves for mid-rise unreinforced masonry buildings.

The earthquake is modeled by means of an elastic response spectrum with a $5 \%$ damping ratio. When the building enters in the nonlinear range it is necessary to consider the effect of the ductility, which is defined
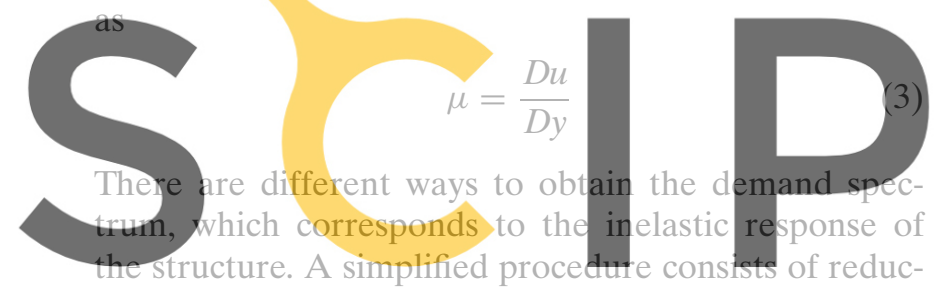

ing the elastic response spectrum $S_{\mathrm{ae}}$ by the ductility

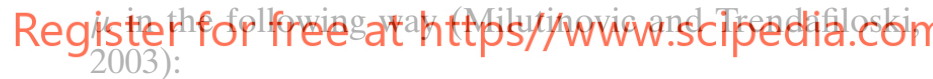

$$
\begin{aligned}
& S_{\mathrm{a}}(T)=\frac{S_{\mathrm{ae}}(T)}{R_{\mu}} \\
& S_{\mathrm{d}}(T)=\frac{\mu}{R_{\mu}} S_{\mathrm{de}}(T)=\mu \frac{T^{2}}{4 \pi^{2}} S_{\mathrm{a}}(T)
\end{aligned}
$$

Table 4

Parameters characterizing the fragility curves, for reinforced concrete buildings (RC) and unreinforced masonry

\begin{tabular}{|c|c|c|c|c|c|c|c|c|}
\hline \multirow[b]{2}{*}{ Building class } & \multicolumn{8}{|c|}{ Damage states thresholds } \\
\hline & $\begin{array}{c}\overline{S d_{1}} \\
(\mathrm{~cm})\end{array}$ & $\beta_{1}$ & $\begin{array}{l}\overline{S d_{2}} \\
(\mathrm{~cm})\end{array}$ & $\beta_{2}$ & $\begin{array}{l}\overline{S d_{3}} \\
(\mathrm{~cm})\end{array}$ & $\beta_{3}$ & $\begin{array}{l}\overline{S d_{4}} \\
(\mathrm{~cm})\end{array}$ & $\beta_{4}$ \\
\hline Low-rise RC & 0.49 & 0.28 & 0.70 & 0.37 & 1.84 & 0.82 & 5.24 & 0.83 \\
\hline Mid-rise RC & 0.99 & 0.28 & 1.42 & 0.36 & 2.34 & 0.50 & 5.11 & 0.61 \\
\hline High-rise RC & 1.33 & 0.28 & 1.89 & 0.29 & 2.59 & 0.34 & 4.68 & 0.45 \\
\hline Low-rise $\mathrm{M}$ & 0.19 & 0.28 & 0.27 & 0.37 & 0.54 & 0.54 & 1.36 & 0.72 \\
\hline Mid-rise M & 0.44 & 0.40 & 0.63 & 0.50 & 1.20 & 0.75 & 2.91 & 0.70 \\
\hline High-rise $\mathrm{M}$ & 0.46 & 0.30 & 0.68 & 0.65 & 1.68 & 0.65 & 2.61 & 0.65 \\
\hline
\end{tabular}
buildings (M) where $T$ is the period and $R_{\mu}$ is the strength reduction factor due to ductility. For its simplicity, the bilinear representation was used:

$$
\begin{cases}R_{\mu}=(\mu-1) \frac{T}{T_{C}}+1 & T<T_{C} \\ R_{\mu}=\mu & T \geq T_{C}\end{cases}
$$

$T_{C}$ is a characteristic period of the ground motion for which the constant acceleration segment passes to a constant velocity segment. The typical values of $T_{C}$, are between 0.6 and 0.7 seconds (Fajfar, 2002).

ATC-40 (1996) provides three procedures to calculate the performance point. All of them lead to similar results. Figure 13 shows a calculation example of the performance point by using an analytical procedure, but it can be seen that the same result is obtained by applying the equal displacement approach. This approach assumes a bilinear elasto-plastic capacity spectrum and that the spectral displacement is the same as if the structure would have an elastic behavior.

\subsection{Damage probability matrices}

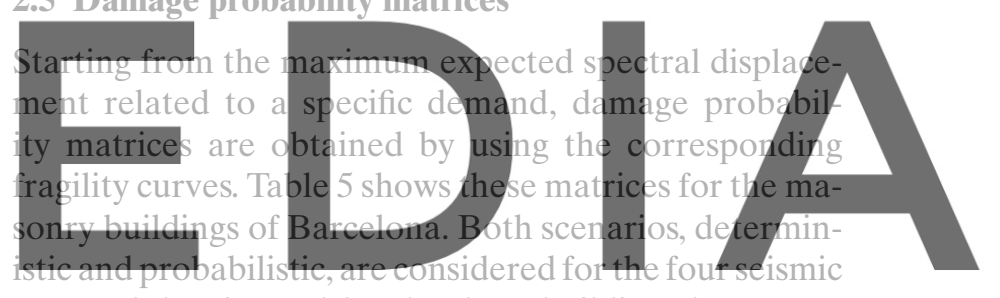

zones of the city and for the three building classes cor-

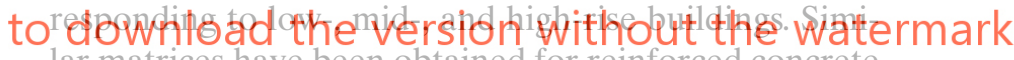 lar matrices have been obtained for reinforced concrete} buildings. In Table 5, DS $S_{m}$ is a weighted average damage state caiculated by using the following equation:

$$
D S_{m}=\sum_{i=0}^{4} D S_{i} P\left[D S_{i}\right]
$$

where $D S_{i}$ takes the values $0,1,2,3$, and 4 for the damage states $i$ considered in the analysis and $P\left[D S_{i}\right]$ are the corresponding probabilities. It can be considered that $D S_{m}$ is close to the most likely damage state of the structure. According to Equation (6), a value $D S_{m}=1.3$, for example, indicates that the most probable damage state of the corresponding building ranges between slight and moderate, the more probable being the slight damage state. This sort of average damage state allows us to plot seismic damage scenarios by using a single parameter. Of course, alternative maps may plot the spatial distribution of the probability of occurrence of a specified damage state, that is $P\left[D S_{i}\right]$ for a given damage state $i$. It can be seen how the expected damage for a relatively small earthquake can be relatively high. For the deterministic scenario, there is a probability of $0.281+0.178=0.459$, 


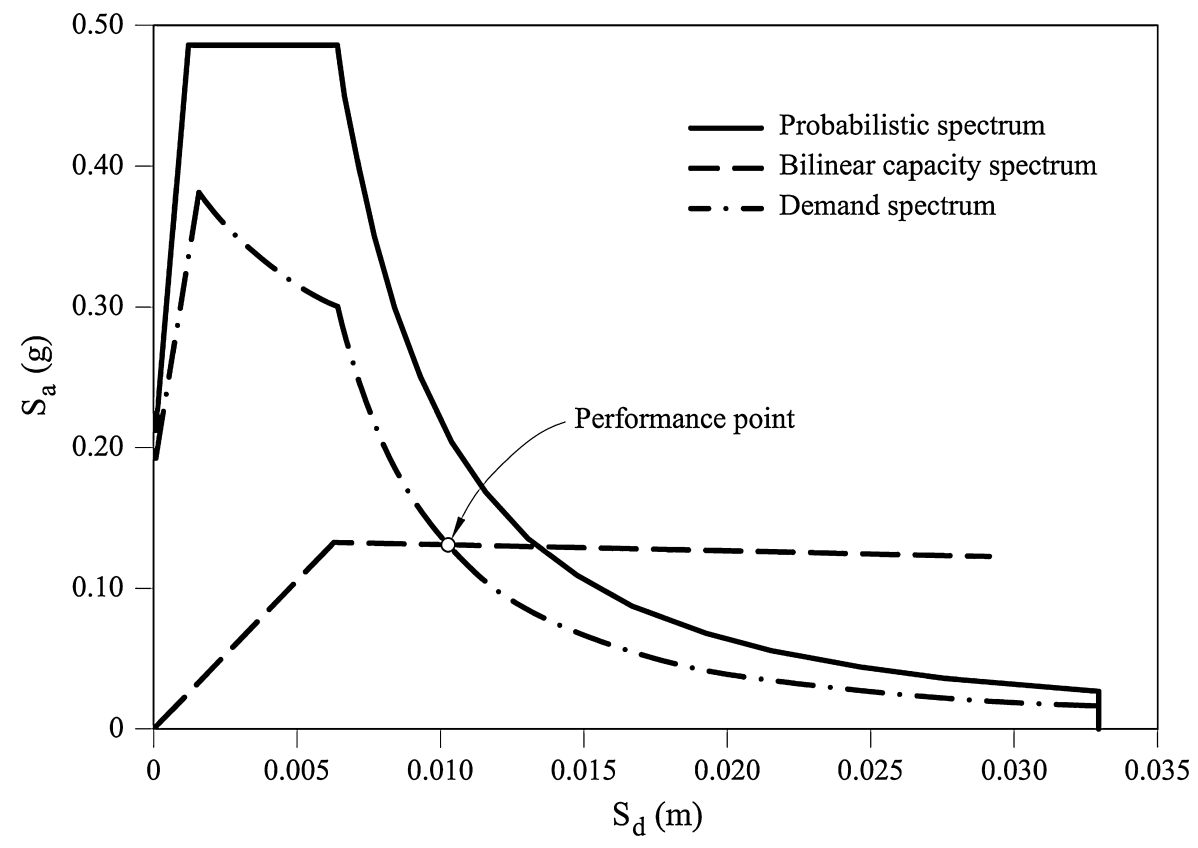

Fig. 13. Example for obtaining the performance point (ATC-40, 1996).

that high-rise unreinforced masonry buildings located in zone II show a damage state between moderate and severe (see Table 5), due to the high vulnerability of this type.

According to EMS-98 (Grünthal, 1998), and the calculated damage probability matrices of Table 5 , the vulner- ability of most of the residential buildings of Barcelona may be included in the vulnerability classes B and C in a scale ranging from A (very high) to $\mathrm{F}$ (very low). EMS-98 predicts significant damage for these buildings and for low macroseismic intensities like VI and even V. Note that macroseismic scales are based on real damage

Table 5

Damage probability matrices (DPM) for masonry buildings for deterministic and probabilistic hazard scenarios

\begin{tabular}{|c|c|c|c|c|c|c|c|c|c|c|c|c|c|}
\hline & \multirow[b]{3}{*}{ Zone } & \multicolumn{6}{|c|}{ Deterministic hazard scenario } & \multicolumn{6}{|c|}{ Probabilistic hazard scenario } \\
\hline & & \multicolumn{5}{|c|}{ Damage state probabilities } & \multirow[b]{2}{*}{$D S_{m}$} & \multicolumn{5}{|c|}{ Damage state probabilities } & \multirow[b]{2}{*}{$D S_{m}$} \\
\hline & & 0 & 1 & 2 & 3 & 4 & & 0 & 1 & 2 & 3 & 4 & \\
\hline \multirow[t]{4}{*}{ Low rise } & I & 0.950 & 0.037 & 0.011 & 0.002 & 0.000 & 0.066 & 0.632 & 0.257 & 0.095 & 0.014 & 0.002 & 0.498 \\
\hline & II & 0.737 & 0.189 & 0.063 & 0.009 & 0.001 & 0.349 & 0.287 & 0.416 & 0.249 & 0.042 & 0.006 & 1.065 \\
\hline & III & 0.917 & 0.061 & 0.018 & 0.003 & 0.001 & 0.109 & 0.431 & 0.365 & 0.173 & 0.027 & 0.004 & 0.807 \\
\hline & $\mathrm{R}$ & 1.000 & 0.000 & 0.000 & 0.000 & 0.000 & 0.001 & 0.981 & 0.013 & 0.004 & 0.002 & 0.000 & 0.025 \\
\hline \multirow[t]{4}{*}{ Mid rise } & I & 0.003 & 0.166 & 0.399 & 0.353 & 0.079 & 2.339 & 0.000 & 0.032 & 0.322 & 0.453 & 0.193 & 2.807 \\
\hline & II & 0.121 & 0.384 & 0.289 & 0.189 & 0.017 & 1.598 & 0.007 & 0.160 & 0.419 & 0.347 & 0.067 & 2.306 \\
\hline & III & 0.273 & 0.364 & 0.215 & 0.139 & 0.009 & 1.247 & 0.029 & 0.270 & 0.395 & 0.271 & 0.035 & 2.012 \\
\hline & $\mathrm{R}$ & 0.623 & 0.193 & 0.105 & 0.076 & 0.003 & 0.642 & 0.109 & 0.391 & 0.305 & 0.181 & 0.014 & 1.600 \\
\hline \multirow[t]{4}{*}{ High rise } & I & 0.003 & 0.145 & 0.389 & 0.371 & 0.092 & 2.404 & 0.000 & 0.019 & 0.248 & 0.464 & 0.269 & 2.983 \\
\hline & II & 0.135 & 0.388 & 0.281 & 0.178 & 0.018 & 1.556 & 0.002 & 0.133 & 0.385 & 0.381 & 0.099 & 2.441 \\
\hline & III & 0.307 & 0.369 & 0.195 & 0.120 & 0.009 & 1.155 & 0.014 & 0.23 & 0.386 & 0.307 & 0.056 & 2.154 \\
\hline & $\mathrm{R}$ & 0.647 & 0.205 & 0.086 & 0.059 & 0.003 & 0.566 & 0.632 & 0.257 & 0.095 & 0.014 & 0.002 & 0.498 \\
\hline
\end{tabular}

Zones corresponding to the seismic microzonation of the city: $\mathrm{R}=$ rocky outcrops, $\mathrm{I}=$ soft soils. Damage states: 0-none, 1-slight, 2-moderate, 3-severe, 4-complete.

$D S_{m}$ : weighted mean damage state. 


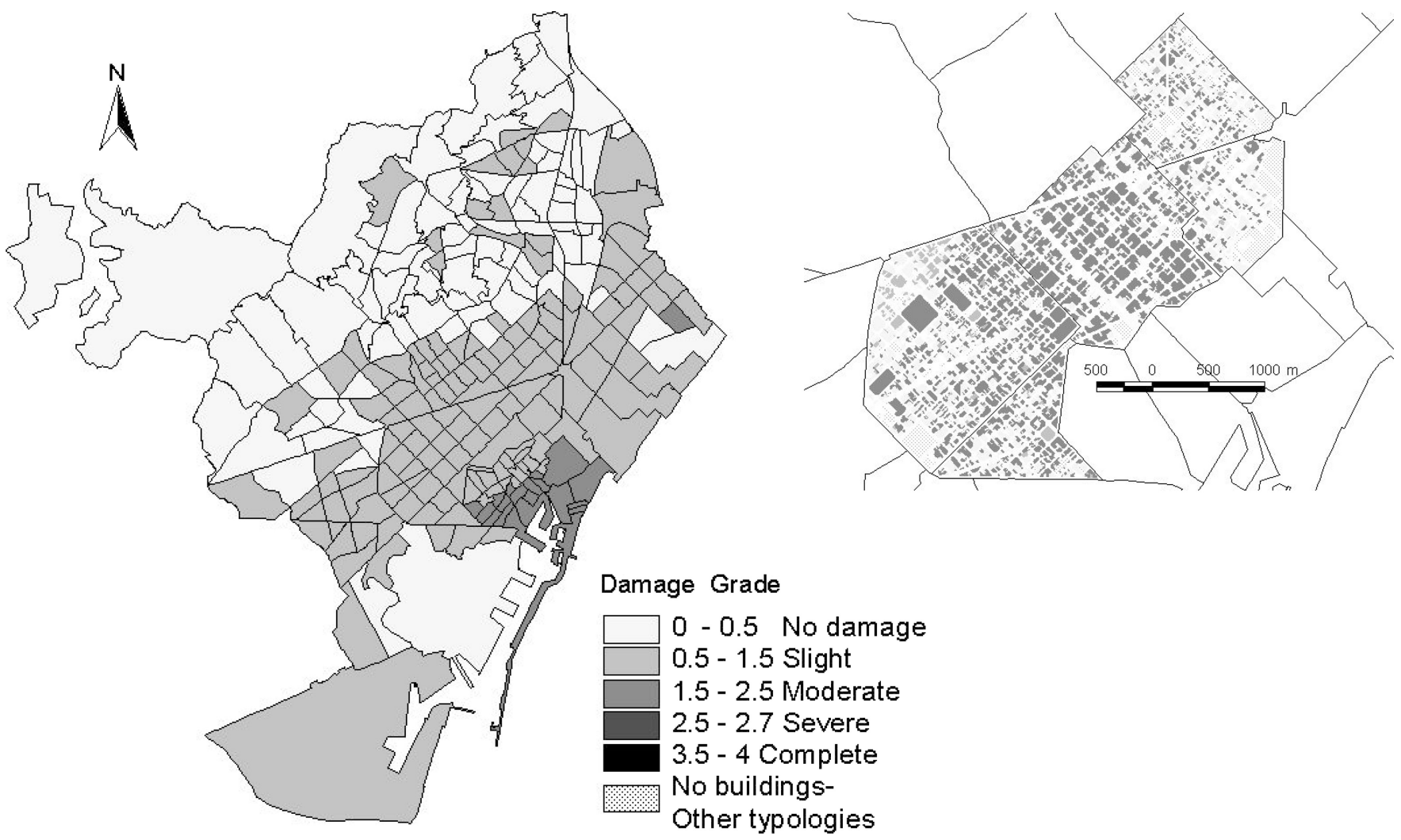

Fig. 14. Damage scenario corresponding to the deterministic hazard scenario. A detail is also shown for the Eixample district.

data observed during past earthquakes, covering a wide period of time and a wide range of earthquake sizes and building classes.

\section{RISK SCENARIOS}

\subsection{Physical damage}

This section is devoted to the evaluation of seismic damage of current buildings and to the simulation and discussion of the seismic risk scenarios of Barcelona. Figure 14 depicts the physical seismic risk scenario for the case of the deterministic hazard scenario.

Figures 15 and 16 are examples of risk scenarios showing the probability for given damage levels. These figures display the probability distribution in the Eixample district, for the damage states moderate and severe, respectively. It has to be noticed that more than $70 \%$ of the buildings in this district are old unreinforced, highrise masonry buildings, and all of them are located in zone II. Thus, according to the values in Table 5, for the deterministic case, the occurrence probability of the moderate damage state is 0.281 , greater than the occurrence probability of the severe damage state case that is
0.178. Figure 17 shows risk scenarios corresponding to the probabilistic hazard scenario.

As can be seen in Table 5 and in Figures 14 and 17, the probabilistic hazard scenario is more damaging than the deterministic one, a fact that is typical in countries with low to moderate seismic hazard. Sets of maps like those of Figures 14-17 are available for the entire city, districts, neighborhoods, and census zones. In this way, it is possible to develop any type of detailed seismic risk scenarios for any seismic hazard case.

\subsection{Casualties, debris, and economic cost}

Once the direct physical damage has been obtained, simplified procedures can be adopted to develop other scenarios of interest, namely for casualties, debris, and economic cost. Examples are given in this section for the case of a credible seismic event in Barcelona. Table 6 summarizes some quantities related to the built area and the average number of storeys for the building classes of Barcelona. These values are necessary in computing the mentioned risk scenarios. It can be observed that the total number of masonry buildings is about four times bigger than the number of reinforced concrete buildings. But the height of reinforced concrete buildings is about 


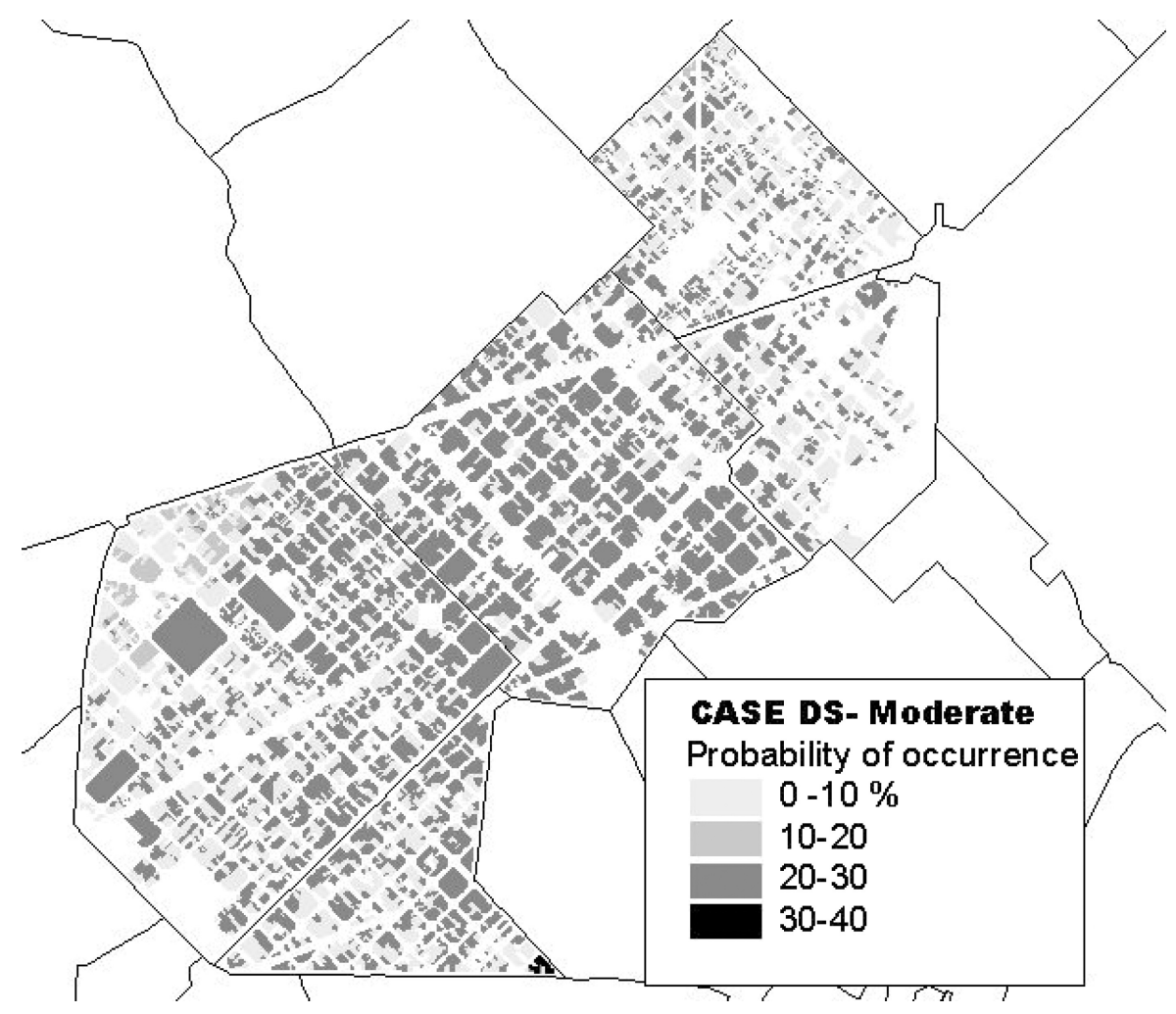

Fig. 15. Probabilities of the moderate damage state in the Eixample District (deterministic hazard scenario).

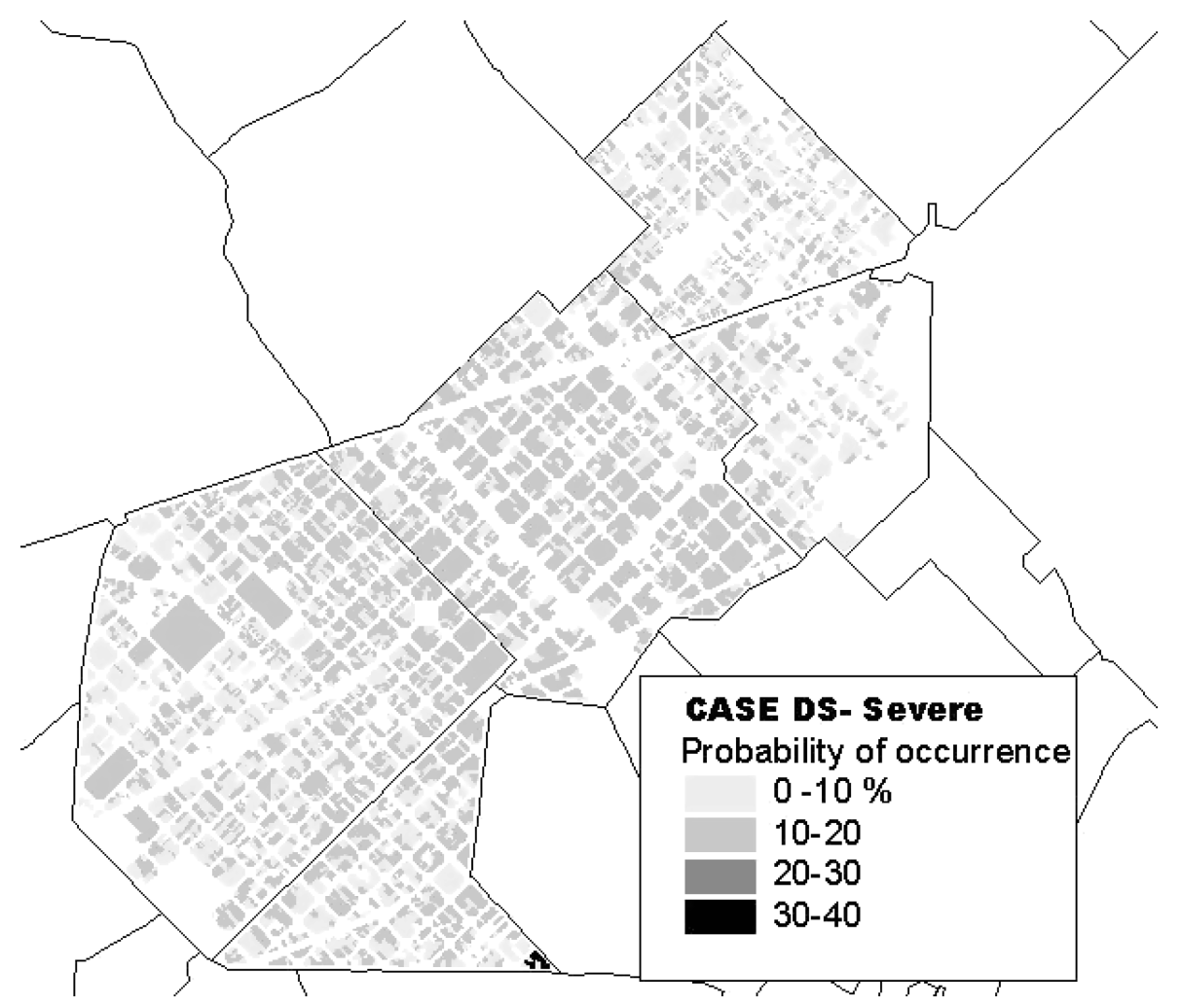

Fig. 16. Probabilities of the severe damage state in the Eixample district (deterministic hazard scenario). 


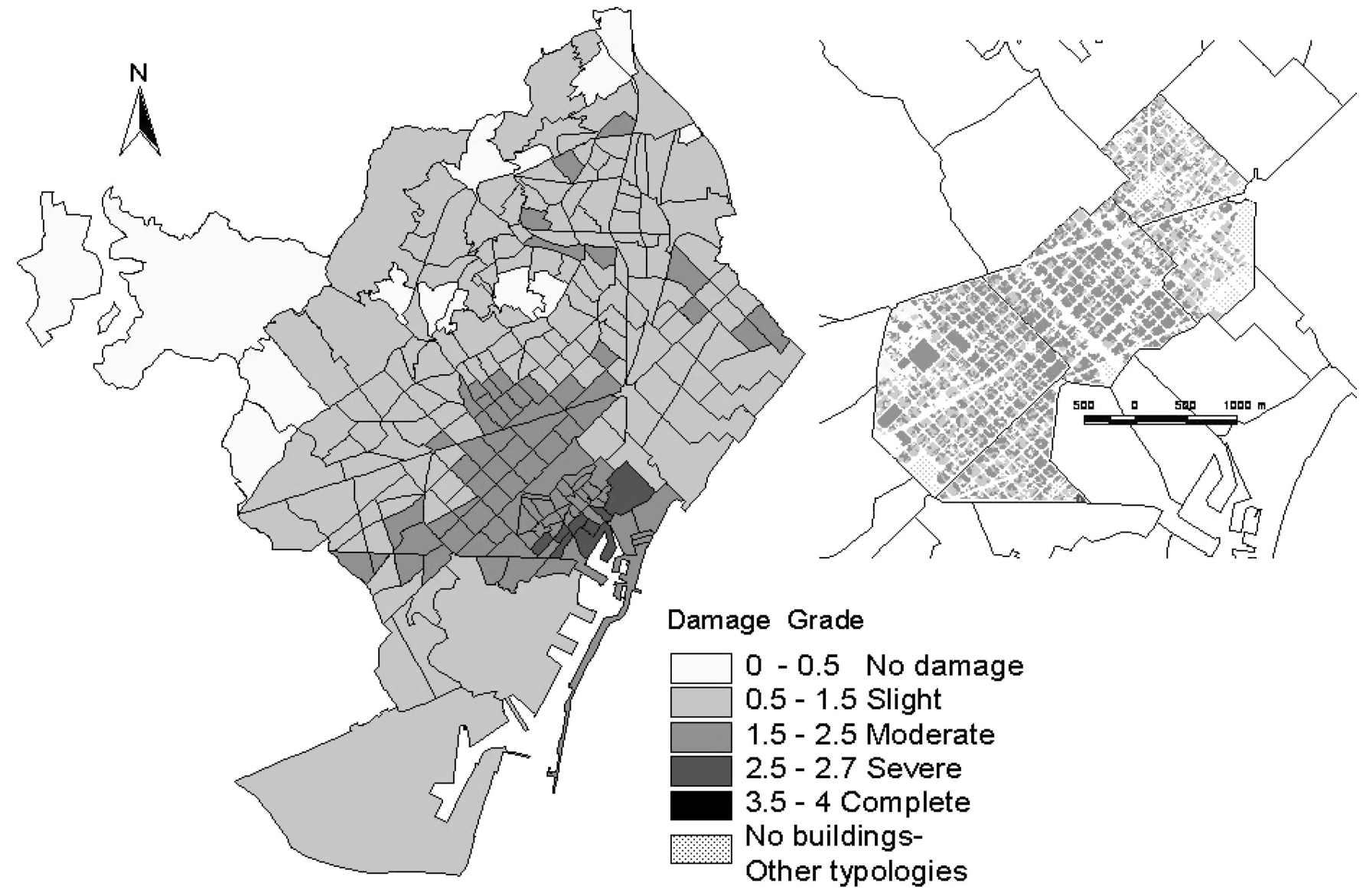

Fig. 17. Probabilistic damage scenario. A detail of the Eixample district is also shown.

twice that of the masonry buildings. Finally, the floor areas for masonry and for reinforced concrete buildings are similar, indicating the bigger size of the reinforced concrete buildings when compared with the masonry buildings. Consequently, the number of dwellings per reinforced concrete building is higher than the number of dwellings per unreinforced masonry building.

Damage to population is first analyzed, considering deceased and injured people. To evaluate the expected number of deaths, the casualty model given by Coburn and Spence (2002) has been applied. These authors pointed out that casualty numbers estimation is ex-

Table 6

Number of buildings, floor built area, and number of storeys in Barcelona

\begin{tabular}{lcc}
\hline & Masonry & Concrete \\
\hline Number of buildings & 47928 & 12725 \\
Floor area (millions $\mathrm{m}^{2}$ ) & 39.6366 & 36.0702 \\
Average number of storeys & 4 & 7 \\
\hline
\end{tabular}

tremely difficult due to its high variability with the earthquakes characteristics and to the lack of reliable data concerning casualties. Over $75 \%$ of deaths are caused by building collapse although up to $25 \%$ are due to nonstructural causes. If earthquake-related secondary disasters are excluded, the building collapse is responsible for about $90 \%$ of the fatalities. In this work, the number of casualties is estimated by using the following equation (Coburn and Spence, 2002):

$$
K s=C[M 1 M 2 M 3(M 4+M 5(1-M 4))]
$$

In this equation, $K s$ is the number of casualties; $C$ is the number of collapsed buildings, evaluated by summing, for all building classes, the number of buildings of the class multiplied by the complete damage state or collapse probability; $M 1$ is the occupancy rate, that is, number of people per building; factor $M 2$ is the occupancy at time of earthquake, and an average value of $65 \%$ for residential buildings is assumed here; factor $M 3$ represents the percentage of occupants trapped by collapse; factor M4 is the percentage of fatalities among those trapped during the earthquake and strongly depends on the 
building type; finally, factor M5 represents the mortality post collapse.

A rough estimation of the expected fatalities for the deterministic hazard scenario is performed by using Equation (7) for the following values of the factors:

- $C=69,000 \times 0.079=5,451$, where 69,000 is a slight overestimate of the number of residential buildings in Barcelona and 0.079 is the probability of a complete damage state for mid-rise masonry buildings placed on soft soils (seismic zone I, according to Figure 4), as it can be seen in Table 5.

- $M 1=22.7$ is the number of inhabitants per building. This value is obtained by assuming 2.24 inhabitants per housing unit and 700,000 housing units in 69,000 buildings (Departament d'Estadística, 2000).

- $M 2=65 \%$ is the occupancy rate at the time of the earthquake as said above.

- M3 $=5 \%$, value which corresponds to nonearthquake resistant masonry buildings and a macroseismic intensity VII in the EMS-98 scale (Coburn and Spence, 2002).

- $M 4=15 \%$, value corresponding to dead or unsavable people, obtained by averaging the values corresponding to low-strength masonry buildings.

- $M 5=60 \%$ corresponds to a community capable of organizing rescue activities and to masonry buildings.

For these values, the number of fatalities of 2,654 has been obtained, which should be understood as an estimate of the order of magnitude of the expected fatalities. For the probabilistic case, the corresponding number of deceased people is 6,484 .

Based on the human loses after strong earthquakes in the twentieth century, Smardjieva and Badal (2002) developed the following statistical correlation between the number of casualties and the earthquake magnitude as a function of population density:

$$
\log N_{k}(D)=a(D)+b(D) M
$$

In this equation, $N_{k}$ is the total number of human losses, $M$ is the magnitude, $a$ and $b$ are parameters which depend on population density $D$. The maximum population density considered in their study is 200 people per $\mathrm{km}^{2}$ and, in this case, $a=-2.09$ and $b=0.86$. Therefore, the numbers of expected deceased during earthquakes with a magnitude of 5.5, 6, and 6.5 are, respectively, 436, 1,175 , and 3,162 . For our study, this procedure for casualty number estimation has been used to compare our simulated results with results based on observed data. Taking into account the density of Barcelona - about 15,000 people per $\mathrm{km}^{2}$ - and the high quality and high amount of input data involved in the model used in this study, it is concluded that this first estimated value of 2,654 is reasonable.
Table 7

Assumed values for coefficients in Equation (7) (adapted from Coburn and Spence, 2002)

\begin{tabular}{lcccc}
\hline & $M 2(\%)$ & $M 3(\%)$ & $M 4(\%)$ & $M 5(\%)$ \\
\hline Masonry buildings & 65 & 5 & 15 & 60 \\
Concrete buildings & 65 & 50 & 40 & 90 \\
\hline
\end{tabular}

In addition to the severity of the hazard scenario, expected casualties in an urban area are strongly correlated with two crucial features of the city: population density and built area. For lower intensity scenarios it is likely to obtain lower values for coefficient $C$ in Equation (7) and it is difficult to know if the lack of victims is due to the low damage level, to the absence of buildings or to the low population density. Simulations for low severity hazard cases produce sparse and incomplete deaths distribution, not representative for the distribution of population and of the built environment. It is clear that a zero value of coefficient $C$ in Equation (7), in case of an EMS VI intensity hazard scenario, does not allow any useful analysis of deaths distribution. For all these reasons we include simulation results for the probabilistic hazard scenario for which results are relevant, significant, and useful for developing emergency plans.

Table 7 summarizes the values of the parameters in Equation (7) adopted for the deceased people scenario. Figure 18 shows the casualty distribution in the census zones of the city. Table 6 clearly shows that the occupancy rate $M 1$ must be bigger for reinforced concrete buildings than for masonry buildings, because the floor area per building is larger. Taking into account that only a fraction of the floor area reported in Table 6 corresponds to residential dwellings, reasonable weights of $45 \%$ and $55 \%$ were assumed for $M 1$ for masonry and reinforced concrete buildings, respectively; that is, $M 1$ for reinforced concrete buildings is 1.22 times the occupation rate for masonry buildings. This assumption is consistent with statistical data concerning the population distribution in masonry and reinforced concrete buildings in zones where they are available. This way of weighing the occupation rate proved to be an adequate procedure allowing developing casualties scenarios. For each census zone, specific $M 1$ values were estimated by using the number of masonry and reinforced concrete buildings as well as the number of inhabitants. Considering for Barcelona the numbers of 1,568,000 inhabitants, 47,928 masonry buildings, and 12,725 concrete buildings, the value of $M 1$ is 24.7 for masonry buildings and 30.2 for concrete buildings.

To calculate fatalities scenarios, the values for $M 2$ M5 given in Table 7 have been used. Note that the coefficients M3-M5 are greater for reinforced concrete buildings than for unreinforced masonry buildings; 


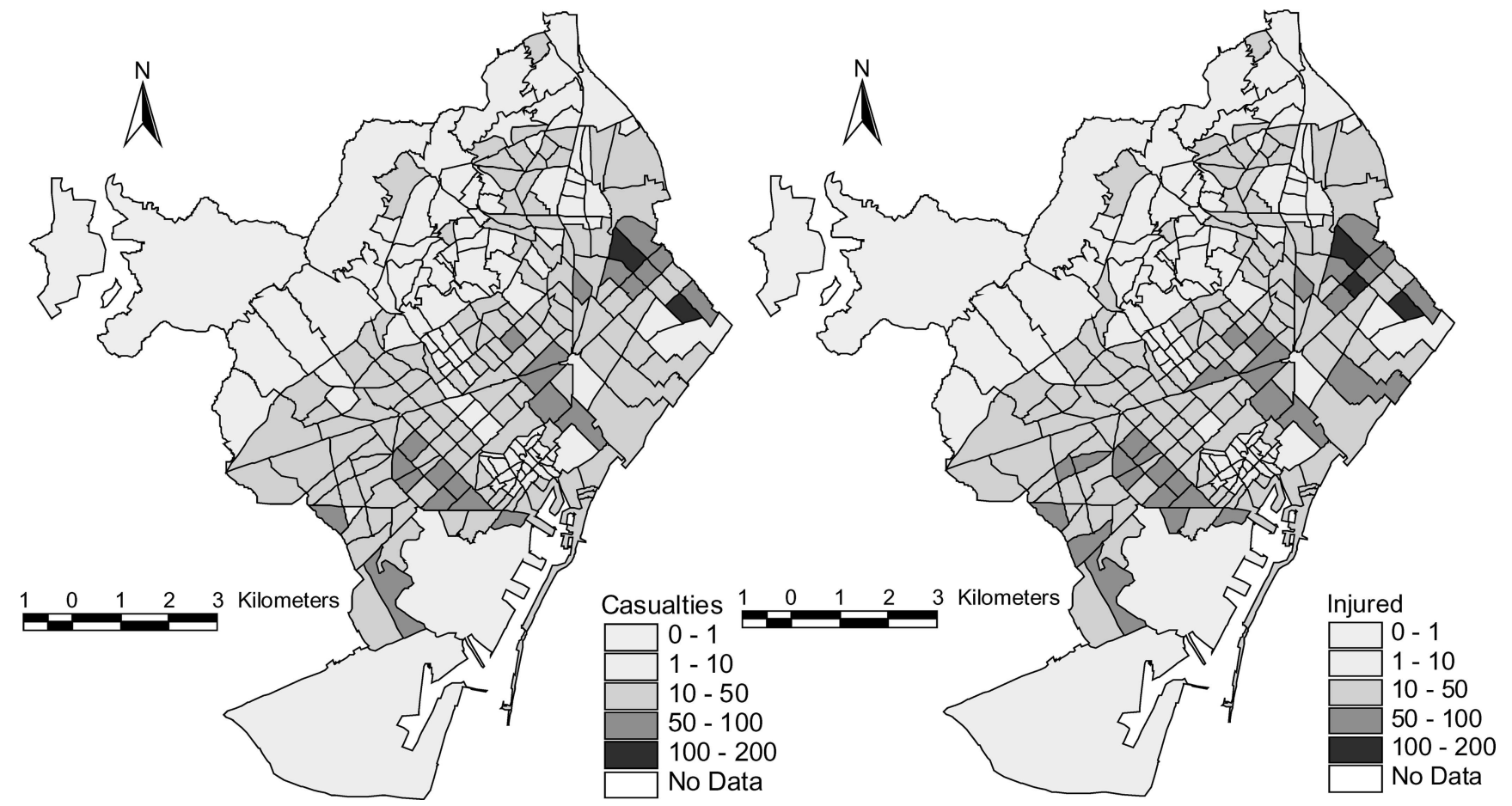

Fig. 18. (a) Scenarios of deceased and (b) severely injured people for census zones. The probabilistic earthquake hazard scenario has been used to evaluate the expected physical damage.

differences are especially significant for the values of coefficients $M 3$ and $M 4$.

Then Equation (7) has been applied to each census zone, providing the scenario of Figure 18a. An analogue procedure has been applied to estimate the number of life-threatening cases needing immediate medical attention. In this case, the only value that changes is $M 4$ in Table 7, which has to be set to $25 \%$ for masonry buildings and 10\% for reinforced concrete buildings (Coburn and Spence, 2002). Figure 18b shows the obtained map.

It can be seen that the simulated probabilistic scenario is more severe and also that the cause of most of the injured and dead people is the collapse of reinforced concrete buildings. This fact is mainly due to the differences in the coefficients $M 3$ and $M 4$ of Table 7, as said above, but it also reveals which was the actual effect of the collapse of certain types of reinforced concrete buildings during past earthquakes (Coburn and Spence, 2002).

The estimation of debris is performed empirically, based on observations of damage that occurred in past earthquakes, for the damage states of the structural and nonstructural elements (Hazus 99-SR2, 2002). Two types of debris are considered: the first is debris that falls in large pieces, for example, steel members or reinforced concrete elements; the second is smaller, such as brick, wood, glass, building contents, etc. Debris scenarios are obtained on the basis of the expected debris fraction that a building class $k$ and debris type $i$ will produce due to the structural damage state $d_{S}$. This fraction is modeled by the following equation:

$$
E D F_{S}(i, k)=\sum_{j=2}^{5} P_{S}(j, k) D F_{S}(i, j, k)
$$

where $E D F_{S}(i, k)$ is the expected debris fraction of debris type $i$ caused by the structural damage suffered by a building of type $k ; P_{S}(j, k)$ is the probability of a structural damage state $j$ for the building class $k$; and $D F_{S}(i, j$, $k$ ) is the fraction of debris type $i$ for the building class $k$ if the structural damage state $j$ occurs. This debris fraction is calculated by means of the following equation:

$$
D F_{S}(i, j, k)=W E(i, k) G F_{S}(i, j, k)
$$

where $W E(i, k)$ are the structural element weights for materials of type $i$ and for the building type $k$. These coefficients are given in Table 8. $G F_{S}(i, j, k)$ are the fractions

Table 8

Weight for structural elements (in ton per $\mathrm{m}^{2}$ ) to be used in the calculation of the debris quantities (adapted from $H A Z U S$ 1999)

\begin{tabular}{lcc}
\hline Building class & $\begin{array}{c}\text { Brick, wood, } \\
\text { and others }\end{array}$ & $\begin{array}{c}\text { Reinforced concrete } \\
\text { and steel }\end{array}$ \\
\hline M3.1, M3.2, M3.3, M3.4 & 0.38 ton per $\mathrm{m}^{2}$ & 0.45 ton per $\mathrm{m}^{2}$ \\
RC3.2 & 0.20 ton per $\mathrm{m}^{2}$ & 0.90 ton per $\mathrm{m}^{2}$ \\
\hline
\end{tabular}


Table 9

Debris generated from damaged structural elements, in fraction of weight (adapted from $H A Z U S, 1999)$

\begin{tabular}{|c|c|c|c|c|c|}
\hline \multirow[b]{2}{*}{ Debris type } & \multirow[b]{2}{*}{ Building class } & \multicolumn{4}{|c|}{ Damage states } \\
\hline & & Slight & Moderate & Extensive & Complete \\
\hline \multirow{2}{*}{$\begin{array}{l}\text { Brick, wood, and } \\
\text { other debris }\end{array}$} & M3.1, M3.2, M3.3, M3.4 & 0.05 & 0.25 & 0.55 & 1 \\
\hline & $\mathrm{RC} 3.2$ & 0.05 & 0.25 & 0.6 & 1 \\
\hline \multirow{2}{*}{$\begin{array}{l}\text { Reinforced concrete and } \\
\text { wrecked steel }\end{array}$} & M3.1, M3.2, M3.3, M3.4 & 0 & 0.02 & 0.25 & 1 \\
\hline & RC3.2 & 0 & 0.04 & 0.32 & 1 \\
\hline
\end{tabular}

of the structural element weight that is expected to result in debris due to the earthquake and it depends on the damage state $j$, the building class $k$, and the debris type $i$. These coefficients are given in Table 9. Finally, the total debris weight, in tons, is obtained by summing, for each building of class $k$ and for each debris type $i$, the built area multiplied by the $E D F_{S}(i, k)$ debris fraction. Figure 19 depicts the debris scenario for the probabilistic earthquake hazard scenario. As it can be seen in Equation (9), there is a direct correlation between the debris amount and the built area but not with the number of ca- sualties (Figure 18) mainly because debris amount due to an earthquake is not directly related with the population density. In addition, in the assumed model, the number of casualties depends only on the collapse damage state (see Equation 7) while debris is produced by any nonnull damage state (see Equation 9).

Economic cost scenarios are based mainly on the reposition cost of the damaged buildings. Nowadays in Spain construction is a very dynamic economic sector in which building and dwelling prices strongly increase year after year. For example, in 2003 the housing

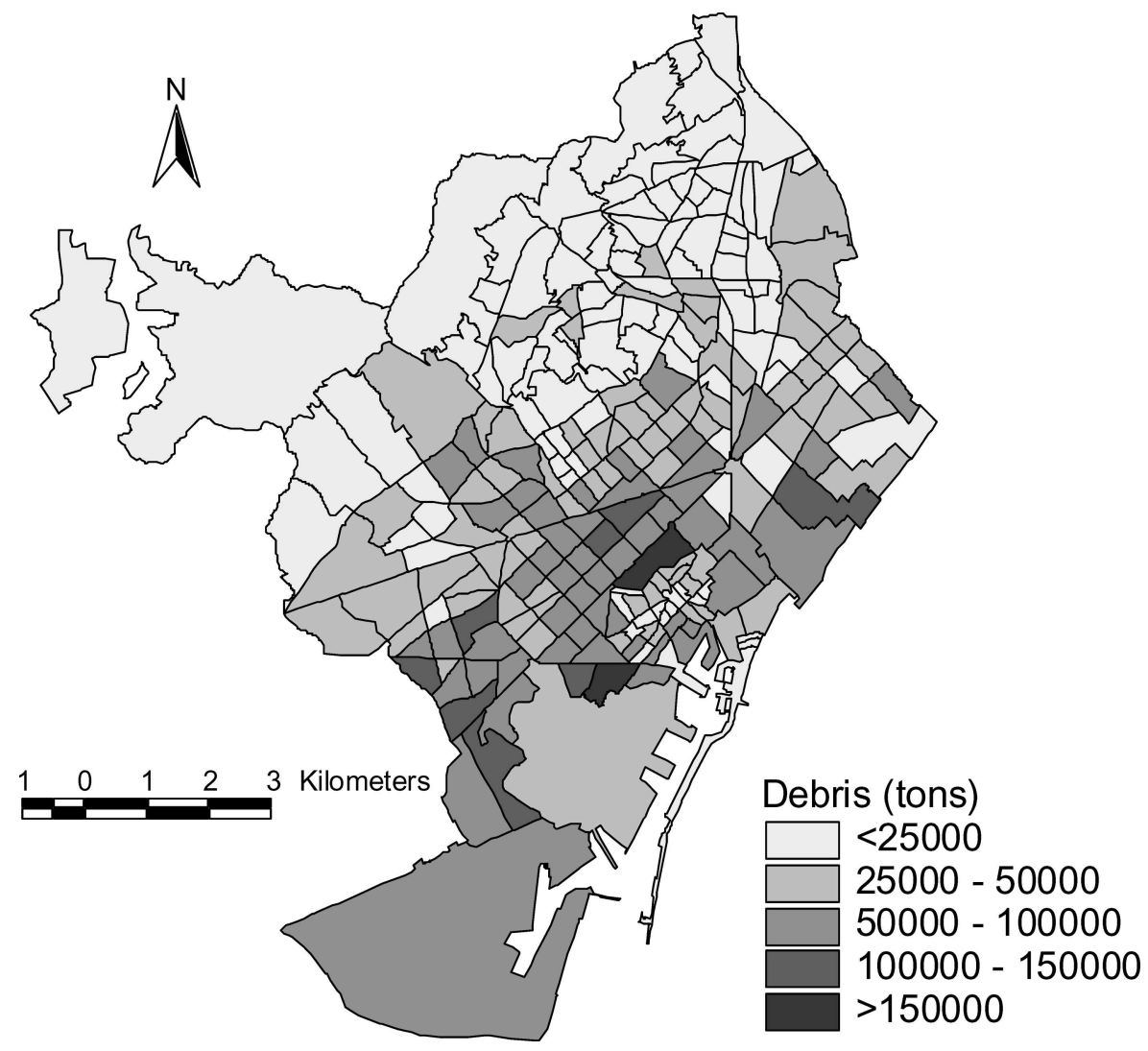

Fig. 19. Debris scenario in Barcelona for the probabilistic earthquake scenario. 
prices increased about $17 \%$ in Barcelona. During the year 2004 , for example, this increase was about $10 \%$. In case of earthquake, the repair cost should probably be not at the free sale price of new or used buildings. Based on these thoughts and considering that the final cost depends on these values, two economic cost scenarios have been evaluated. The first one gives the absolute cost, in million of Euros, while the second one gives the relative economic cost, namely the expected equivalent floor area destroyed by the earthquake. In fact, the step from one scenario to the other can be made by simply multiplying the built square meters by this controversial value, that is, the value of repairing or constructing a new square meter of building. The following equation is used to compute the economic cost of the seismic crisis:

$$
C S(j)=\sum_{k=1}^{N t y p}\left[\operatorname{Area}(k) P_{S}(j, k) R C(j, k) V(k)\right]
$$

where $C S(j)$ is the repair cost due to the damage state $j$; Area $(k)$ is the buildings type $k$ area, $P_{S}(j, k)$ is the probability for the building type $k$ to be in the damage state $j$ and $R C(j, k)$ is the repair value due to the damage state $j$ for the building type $k . R C(j, k)$ is given as a percentage of the reposition cost per square meter. $V(k)$ is this cost per unit area for the building type $k$ for $k=1$ to Ntyp, Ntyp being the number of building types. Column 2 in Table 10 shows the percentage values $R C(j, k)$ and column 3 , in the same table, gives the products $R C(j, k) V(k)$, which have been assumed to be dependent on the damage state $j$ but not on the structural type $k$. Of course, this product corresponding to the complete damage state is $V(k)$, which is reasonably assumed to be constant.

Thus, the total cost due to the damage caused by a seismic crisis in current buildings is given by the following equation:

$$
\text { Cost }=\sum_{j=2}^{5} C S(j)
$$

Table 10

\begin{tabular}{|c|c|c|}
\hline Damage states & Percentages* & $\begin{array}{c}\text { Absolute values }{ }^{\dagger} \\
\left(€ / m^{2}\right)\end{array}$ \\
\hline 1- None & $0 \%$ & 0 \\
\hline 2- Slight & $2 \%$ & 44 \\
\hline 3- Moderate & $10 \%$ & 221 \\
\hline 4- Extensive & $50 \%$ & 1104 \\
\hline 5- Complete & $100 \%$ & 2208 \\
\hline
\end{tabular}

Absolute repair cost per unit area for each damage state

Percentages of repair to reposition cost are also given.

*ATC-13 (1985), ${ }^{\dagger}$ Fomento (2002). where Cost is the sum of the $C S(j)$ repair costs for all the $j$ damage states. Damage state 1 -none is not considered, because there is not any induced cost when there is no damage. Assuming that, as pointed out before, $V(k)=$ Value is the same for all building categories, then Equations (11) and (12) lead to

$$
\text { Cost }=\text { Value } \sum_{j=2}^{5} \sum_{k=1}^{\text {Ntyp }}\left[\operatorname{Area}(k) P_{S}(j, k) R C(j, k)\right]
$$

where Value is the assumed constant cost per unit area independent of the building type. In this case, a relative economic cost $R$ Cost can be defined by

$$
R \text { Cost }=\frac{\text { Cost }}{\text { Value }}=\sum_{j=2}^{5} \sum_{k=1}^{\text {Ntyp }}\left[\operatorname{Area}(k) P_{S}(j, k) R C(j, k)\right]
$$

As given before (Table 10), a reasonable proxy for Value is $2,208 € / \mathrm{m}^{2}$, which has been taken from the official prices in Spain (Fomento, 2002). The left-hand side of Figure 20 depicts the absolute cost scenario, in million Euros, caused by the probabilistic hazard case, while the right-hand side of the same figure shows the relative cost scenario in an equivalent collapsed floor area.

Finally, the additional economic losses due to the damage of the building content can also be considered. From ATC-13 (1985) it is assumed that the value of the content for residential buildings is about $50 \%$ of the building reposition value. Table 11 summarizes the total cost for the probabilistic earthquake scenario considered herein. The total cost of such an earthquake would be more than 46,000 million Euros.

\section{CONCLUSIONS}

A computer-assisted tool for estimating seismic risk scenarios in urban areas, which is useful for damage prediction and for emergency plans design, has been developed. This tool incorporates latest generation methodologies for hazard, damage, and risk estimation. The method has been applied to Barcelona, which is a typical Mediterranean city, located in a low-to-moderate seismic hazard area. Although only residential buildings have been included in this study, the tool can be easily extended to include other essential buildings and facilities. The proposed seismic risk evaluation model requires an accurate definition of the expected seismic action and the characteristics of the built environment as well as data about the population distribution. The most important results are the seismic vulnerability and fragility of the buildings and their expected physical damage as are also estimations of casualties, debris, and economic costs. The proposed approach is based on a building-by-building analysis but it also provides seismic 

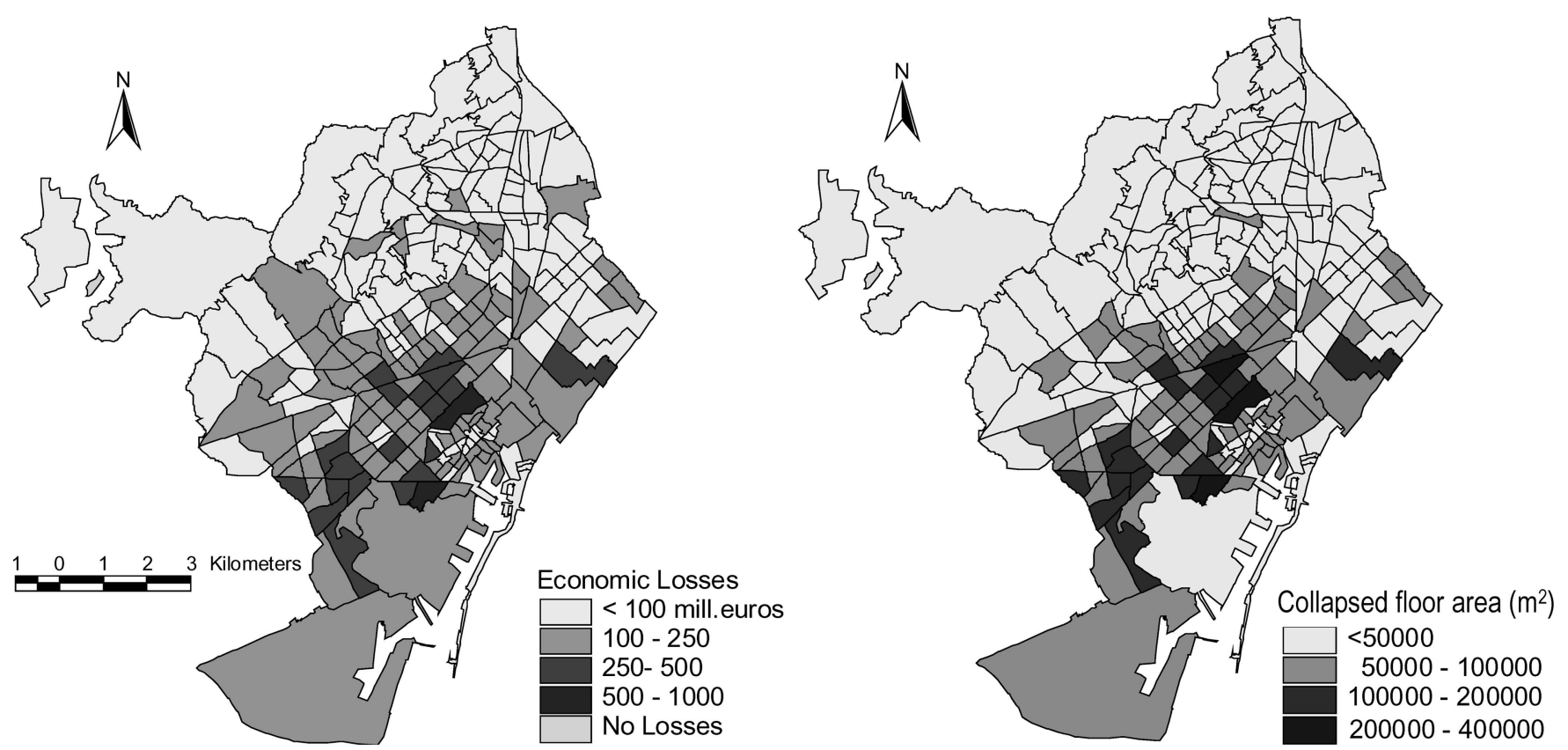

Fig. 20. Economic cost scenarios for Barcelona: absolute cost in millions of Euros (left-hand side map) and relative cost in squared meters (right-hand side map).

risk scenarios mapped according to different territorial or political areas of the city like districts, neighborhoods, and census tracks.

Relevant conclusions referring to the methodological aspects of this work are given in the following. The results that are obtained for the seismic risk of urban areas should include uncertainties involved in all steps of the analysis, which are difficult to estimate. Nevertheless, it was beyond the purpose of this article to analyze the uncertainties and errors in the model. The proposed tool is efficient in mapping average expected risk scenarios, which are satisfactory for damage predictions oriented to urban and emergency planning and risk management. Modern cities are characterized by wide areas with a high density of buildings and populations and, therefore, the enormous number of buildings existing in such urban areas suggests the use of simplified analysis models. These models required classifying the buildings in typological groups characterized by bilinear capacity spectra which can be obtained by using existing computer codes. Capacity curves are developed starting from the hypothesis that the structural response is dominated by the fundamental mode of vibration, which is not valid in the case of very flexible structures having the fundamental period higher than 1 second. This is not the case of current buildings, for which the use of simplified capacity curves together with predetermined demand spectra provides a reasonably good approximation of their expected seismic performance. Fragility curves can also be estimated in a simplified way. Seismic hazard is defined by a $5 \%$ elastic response spectra existing for the studied area, which is the starting point for the calculation of the demand spectra. Seismic microzonation of the urban area allows us to obtain specific damage probability matrices for each seismic zone. Seismic risk scenarios are then obtained by using the aforementioned damage probability matrices. Damage results have to be in agreement with the estimates provided by the macroseismic intensity scales which are based on a wide database of real damage data observed during past earthquakes.

Table 11

Summary of the economic losses in Barcelona for the probabilistic earthquake scenario

\begin{tabular}{|c|c|c|c|c|c|c|c|c|}
\hline & \multicolumn{5}{|c|}{ Damage states } & \multirow{2}{*}{$\begin{array}{c}\text { Structural } \\
\text { damage cost }\end{array}$} & \multirow{2}{*}{$\begin{array}{l}\text { Building content } \\
\text { losses }\end{array}$} & \multirow{2}{*}{$\begin{array}{c}\text { Total direct economic } \\
\text { losses }\end{array}$} \\
\hline & None & Slight & Moderate & Extensive & Complete & & & \\
\hline Cost (million $€)$ & 0 & 678 & 7.320 & 15.011 & 7.904 & 30.913 & 15.456 & 46.369 \\
\hline
\end{tabular}


Therefore, they may be used to validate the simulation results obtained with different models. A wide vulnerability range is expected for both the masonry and the reinforced concrete buildings existing in urban areas.

The main conclusions concerning the numerical simulation of the seismic risk in Barcelona are given here. The highest expected fundamental vibration period of the residential buildings in Barcelona is about 1 second and therefore the limitations of the pushover analysis do not affect the reliability of the damage results obtained for the buildings in Barcelona, which lead to reasonably good approximations of the calculated seismic risk scenarios whose development was the main purpose of this study. Capacity and fragility curves have been developed for more than $95 \%$ of the residential building stock of the city, which is well represented by six building classes. Significant ductility and damage is obtained for mid- and high-rise masonry buildings, due to the slenderness of these buildings. Reinforced concrete buildings also show low seismic capacity leading to significant expected damage, which can be attributed mainly to the columns and slabs structural type. Damage probability matrices have been obtained for four seismic areas of the city, allowing development of representative risk scenarios. The casualty model used in this article is based on semi-empirical formulae. Casualty numbers show a great variability with the characteristics of past earthquakes and are affected by the lack of reliable data. Expected casualties are strongly correlated with the population density and the size of the built area. It is expected that about $75 \%$ of deaths are caused by building collapse and about $25 \%$ by nonstructural causes. The building collapse is responsible for about $90 \%$ of the fatalities. Casualty scenarios are extremely useful for developing emergency plans. No direct correlation has been found between debris amount and number of casualties. Debris amount is well correlated with the total built area while casualties are assumed to be caused only by the collapse of buildings and they are related to the number of inhabitants per dwelling. Developing seismic risk scenarios requires an important amount of high-quality data. The lack of information about the seismic hazard, the built environment or the population complicates or prevents this type of study. In fact, the scenarios developed herein are based on a complete and highly reliable database concerning the current buildings of the city, which has been collected and improved during a decade. The knowledge of the seismic hazard of the studied area is also decisive. Previous seismicity and hazard studies carried out by the Geological Survey of the Catalan Cartographic Institute of Barcelona allowed us to obtain the credible hazard scenarios in response to the spectrum format, which have been used in this work. It is important that the cities promote this kind of study and use their results in their urban planning and seismic risk management activities.

\section{ACKNOWLEDGMENTS}

This work has been partially sponsored by the Spanish Ministry of Education and Science and with FEDER funds (projects: REN2002-03365/RIES, CGL2005-04541-C03-02/BTE, REN2003-07170/RIES, and CGL2004-22325-E) and by the European Commission (RISK-UE Project, contract EVK4-CT-200000014).

\section{REFERENCES}

ATC-13 (1985), Earthquake Damage Evaluation Data for California, ATC Applied Technology Council, Redwood City, California.

ATC-40 (1996), Seismic Evaluation and Retrofit of Concrete Buildings, Applied Technology Council, Report: SSC 9601, Volume 1, Seismic Safety Commission, Redwood City, California.

Barbat, A. H., Lagomarsino, S. \& Pujades, L. G. (2006), Vulnerability assessment of dwelling buildings, in C. Sousa, A. Roca, and X. Goula (eds.), Assessing and Managing Earthquake Risk, Springer, Dordrecht, The Netherlands.

Barbat, A. H., Oller, S., Oñate, E. \& Hanganu, A. (1997), Viscous damage model for Timoshenko beam structures, International Journal of Solids Structures, 34(30), 395376.

Barbat, A. H., Yépez Moya, F. \& Canas, J. A. (1996), Damage scenarios simulation for seismic risk assessment in urban zones, Earthquake Spectra, 12(3), 371-94.

Cardona, O. D. \& Barbat, A. H. (2000), El Riesgo Sísmico y su Prevención, Calidad Siderúrgica, Madrid, Spain.

Carr, A. (2000), Inelastic Dynamic Analysis Program: RUAUMOKO and Post-processor for RUAUMOKO, Department of Civil Engineering, University of Canterbury, New Zealand.

Carreño, M. L., Cardona, O. D. \& Barbat, A. H. (2006), Urban seismic risk evaluation: A holistic approach, Natural Hazards, in press.

Cid, J. (1998), Zonificación sísmica de la ciudad de Barcelona basada en métodos de simulación numérica de efectos locales. Tesis Doctoral, Universidad Politécnica de Cataluña, Barcelona.

Coburn, A. \& Spence, R. (2002), Earthquake Protection, 2nd edn. John Wiley, New York.

Departament d'Estadística (2000), La població de Barcelona, Ajuntament de Barcelona.

Egozcue, J. J., Barbat, A., Canas, J. A., Miquel, J. \& Banda, E. (1991), A method to estimate intensity occurrence probabilities in low seismic activity regions, Earthquake Engineering and Structural Dynamics, 20, 43-60.

Fajfar, P. (2002), Structural analysis in earthquake engineering-A breaktrough of simplified non-linear methods, 12th European Conference on Earthquake Engineering, London.

Fomento (2002), Índice de precios de las viviendas, Ministerio de Fomento, Madrid. 
Galaso, A., Lagomarsino, S. \& Penna, A. (2002), TREMURI Program: Seismic Analysis of 3D Masonry Buildings, University of Genoa, Italy.

Gambarotta, L. \& Lagomarsino, S. (1993), A microcrack damage model for brittle materials. International Journal of Solids and Structures, 30, 177-98.

Grünthal, G. (ed.) (1998), European Macroseismic Scale 1998, Centre Européen de Géodynamique et Séismologie, Cahiers du Centre Européen de Géodynamique et de Séismologie, Volume 15, Luxembourg.

HAZUS 99-SR2 (2002), HAZUS Technical Manual, vol. 13, Federal Emergency Management Agency, FEMA \& National Institute of Building Sciences, NIBS, Washington DC. Infocca (1999), Funcions d'informació de Barcelona $i$ Cartografia, IMI, Ajuntament de Barcelona.

Irizarry, J., Goula, X. Y. \& Susagna, T. (2003), Analytical formulation for the elastic acceleration-displacement response spectra adapted to Barcelona soil conditions, Technical Report, Instituto Cartográfico de Cataluña, Barcelona.
Lungu, D., Aldea, A., Arion, A., Vacareana, R., Petrescu, F. \& Cornea, T. (2001), European distinctive features, inventory database and typology, Work Package 1 of RISK_UE Project, European Commission, EVK4-CT-2000-00014.

Milutinovic, Z. V. \& Trendafiloski, G. S. (2003), Vulnerability of current buildings, Work Package 4 of RISK_UE Project, European Commission, EVK4-CT-2000-00014.

PGS-1 (1968), Norma Sismorresistente P.G.S.-1, Comisión Interministerial de la Presidencia del Gobierno, Decreto 106/1969 de 16 de enero de 1969.

Reinhorn, A. M. (1997), Inelastic analysis techniques in seismic evaluations, in Krawinkler and Fajfar (eds.). Seismic Design Methodologies for the Next Generation of Code, Balkema Publishers, Rotterdam, Netherlands, pp. $277-$ 87.

Smardjieva, E. \& Badal, J. (2002), Estimation of the expected number of casualties caused by strong earthquakes, Bulletin of the Seismological Society of America, 92(6), 2310 22. 